\title{
EL BRAZO MILITAR DE CATALUÑA DURANTE \\ EL PRIMER GOBIERNO DE FELIPE V (1700-1705)
}

\section{The Military Wing of Catalonia during the First Government of Philip V (1700-1705)}

\author{
Eduard MARTÍ ${ }^{1}$ \\ Universitat Internacional de Catalunya \\ emarti@uic.es
}

Fecha de recepción: 5/03/2014

Fecha de aceptación definitiva: 6/05/2014

RESUMEN: En diciembre de 1703 el Brazo Militar se negaba a obedecer la orden de modificación del testamento de Carlos II. Argumentaba para ello el Estamento Militar "Sólo era una junta establecida de nobleza en Cortes, sin tener comunicado tal poder. Llama la atención el concepto tan simple que el Brazo tiene de sí mismo, más si se tienen en cuenta que unos años más tarde, el Conde de Robres consideraba que "ninguno más que ese cuerpo es comprendido en la extirpación de las leyes patrias, decretadas por el señor Felipe V". ¿Cómo es posible estas impresiones tan opuestas? El objetivo de este artículo es analizar la actuación del Brazo Militar de Catalunya durante los años de la Guerra de Sucesión y poner de manifiesto el papel decisivo que tuvo esta institución en la defensa del marco constitucional catalán.

\section{Palabras clave: Brazo militar, Catalunya, Felipe V}

ABSTRACT: In December 1703, the Military Wing in Catalonia refused to obey the order to amend the will of Charles II. They argued that they "were just a board

1. Este trabajo se inserta dentro del proyecto del ministerio "España y los Tratados de Utrecht (1712-1714)" (HAR2011-26769) y del "Grup d'Estudis de les Institucions i la societat a la Catalunya Moderna, segles XVI-XIX" (2009 SGR 00318), dirigidos por el profesor Joaquim Albareda. 
of nobility established in the Cortes which was never informed of such power". This simple concept that the Military Wing had of itself is surprising, and more so if one takes into account that a few years later, the Earl of Robres considered that "no body other than that one is comprised in the removal of the homeland laws enacted by King Philip V". How can such contrasting impressions exist? The aim of this paper is to analyze the performance of the Military Wing of Catalonia during the years of the War of the Spanish Succession and to highlight the crucial role played by this institution in the defense of the Catalonian constitutional framework.

Key words: Military Wing; Catalonia; Philip V; War of the Spanish Succession.

A principios de diciembre de 1703, siguiendo el consejo de la Conferencia de los Tres Comunes, la Diputación, el Consell de Cent y el Brazo Militar de Cataluña escribían a Felipe V informándole que no podían obedecer la orden de modificar el testamento de Carlos II porque la ley no se lo permitía ${ }^{2}$. En la respuesta que dio el Estamento Militar, afirmaba que "solo era una junta establecida de nobleza en Cortes, sin tener comunicado tal poder ${ }^{3}$. Llama la atención el concepto tan simple que el Brazo tiene de sí mismo. Unos años más tarde, en 1708, el Conde de Robres, que había sido presidente del Brazo Militar en 1685 y conocía bien la institución, no dudaba en asegurar que "ninguno más que ese cuerpo es comprendido en la extirpación de las leyes patrias, decretadas por el señor Felipe V, á más de los rigores que temerán como autores principales de los movimientos civiles ${ }^{4}$. Su juicio no está muy alejado del que en marzo de 1713 hacía Àngel Mach, el cual consideraba que "la mayor parte de los caballeros, militares, frailes y enxarpadaos indujeron de tal conformidad en la referida rebelión [...], éstos fueron los que indujeron y parsipitaron los miserables plebeyos en su perdición". Cada vez son más los estudiosos que están desatacando el importante papel que tuvo la nobleza catalana en el posicionamiento austriacista durante la Guerra de Sucesión ${ }^{6}$. Recientemente Antoni Simon nos recordaba que "la direcció política de Barcelona

2. Dietaris de la Generalitat de Catalunya. Barcelona: Generalitat de Catalunya, 2007, vol. 10, p. 350. De ahora en adelante será citado como DGC indicando el volumen.

3. Castellví, Francisco. Narraciones Históricas. 1. ${ }^{a}$ ed. Madrid: Fundación Francisco Elías de Tejada, 1997, 4 vols., vol. I, p. 418.

4. López de Mendoza, Agustín. Historia de las Guerras Civiles de España. 1. ${ }^{a}$ ed. Zaragoza: Diputación Provincial de Zaragoza, 1882, 2 vols., p. 390. De ahora en adelante será citado como Robres, Historia..., indicando la página.

5. Archivo Histórico Nacional (AHN), Estado, 440 (2). Memorial dirigido a José Grimaldo el 23 de marzo de 1713, p. 14.

6. AlBareda, Joaquín. La Guerra de Sucesión de España (1700-1714). Barcelona: Crítica, 2010; SERRA, Eva. "Voluntat de sobirana en un context de canvi dinàstic". En VV. AA. Una relació difícil. Catalunya i l'Espanya Moderna. Barcelona: Editorial Base, 2007, pp. 109-180 y Morales RocA. Francisco. Próceres habilitados en las Cortes del Principado de Catalunya, siglo XVII (1599-1713). Madrid: Hidalguía, 1983. 
i de Catalunya" durante conflicto estuvo "esencialment en mans de la classe dirigent barcelonina, la qual tenia el seu nucli dur en els membres d'un Braç Militar " ${ }^{7}$. El dibujo que nos presenta este historiador es el de una élite cerrada, vinculada por lazos familiares, que posee unos intereses concretos y consigue controlar las instituciones catalanas para sus fines. Se visualiza así una dinámica institucional bastante semejante a lo sucedido en 1640 y 1688, lo que demostraría unas claras continuidades. ¿Fue realmente así?

Este tipo de aproximación, que sin duda tiene un cierto fundamento real, puede chocar con la visión que aportan otros contemporáneos del momento. José Alós, otro veterano de la institución ${ }^{8}$, afirmaba en 1706 que en los últimos tiempos el Brazo empezaba a "interesarse en las dependencias, [...] que recaen sobre rompimiento de las leyes, fueros, inmunidades y libertades de Cathalunya, de la cuales se constituye el Brazo Militar zelador"?. Una nobleza que para un memorialista anónimo de 1705 era "la más cualificadas y la más querida y estimada de la plebe ${ }^{10}$. Este tipo de afirmaciones hablan del Brazo Militar como una institución muy respetada que, a finales del siglo XVII, empezó a tener un protagonismo cada vez mayor en cuestiones políticas. En este sentido, cabe preguntarse si la oposición de la nobleza catalana a Felipe V obedece a la actividad de un grupo de personas concretas, que dominó la institución, o si por el contrario, responde a dinámicas más complejas y significativamente más relevantes.

Los estudios del papel de la nobleza catalana durante la contienda bélica suelen basarse en las memorias de los principales protagonistas, tanto de un bando como otro $^{11}$, así como la correspondencia personal o las deliberaciones del Consejo de Estado. Estos relatos pueden confundir al lector, ya que tienden a identificar dos realidades que son semejantes pero no idénticas: nobleza y Brazo Militar. Un tema es la actuación de un noble o un grupo de ellos y otra, netamente diferente, es el conjunto de decisiones que tomó el Estamento. Estas últimas son el resultado de un debate interno, lo cual tiene una mayor representatividad y significación política. Por esta razón, para poder valorar de manera adecuada el papel de la

7. Simón i TARres, Antoni. Del 1640 al 1705. Valencia: Publicacions Universitat de Valencia, 2011, p. 298.

8. José Alós había sido consejero militar el Brazo en 1689. Cfr. MARTí, Eduard. La classe dirigent catalana. Barcelona: Fundació Noguera, 2009, p. 80.

9. GAY, Josep María. El corregidor a Catalunya. Madrid: Marcial Pons, 1997, p. 755.

10. BARREDa Fontes, José M. y CARretero ZAMOra, Juan M. "Una fuente inédita sobre la Guerra de Sucesión: memoria anónima sobre el sitio de Barcelona de 1705". Hispania, 1980, 40, pp. 631-668. La cita está en la p. 667.

11. Además de los citados anteriormente, son de lectura imprescindible también BaLLCALLAR y SANA, Vicente. Comentarios de la guerra de España. Madrid: Atlas, 1957; Feliu DE la PENYA, Narcís. Anales de Catalunya. Edición facsímil. Barcelona: Base, 1999. En adelante lo citaremos como Feliu de la Penya. Anales...; MAS, Emmanuel. Diari des del novembre del any 1700 fins a l'octubre del any 1705, Biblioteca del Seminario Consular de Barcelona, Documento 419. En adelante lo citaremos como Mas, E. Diari... 
nobleza catalana en el conflicto resulta necesario hacer una aproximación a través de la documentación oficial del mismo Brazo Militar. Así, el relato adquiere una mayor normalidad institucional ${ }^{12}$. El presente trabajo tiene este objetivo. Para ello, primeramente haremos una breve explicación de la naturaleza del Brazo Militar y su asentamiento institucional en la segunda mitad del siglo XVII, y luego nos adentraremos en las principales actuaciones políticas entre 1700-1705.

\section{El BRAZO Militar de CATAluña}

El origen del Brazo Militar de Cataluña se remonta a la pragmática que Juan II concedió al Estamento en las Cortes de 1389, por la cual se dividía el Brazo en dos: uno de caballeros y otros de nobles. El primero, denominado de "Militibus, Generosis \& Hominibus de Paratico" tenía la facultad de reunirse fuera de Cortes, hacer ordinaciones, tener oficiales y sello propio ${ }^{13}$. Este primer Brazo tuvo una historia muy corta y casi no ha dejado rastro ${ }^{14}$. No es hasta 1602 cuando se produce una "refundación" del Estamento, y se dota de unos nuevos estatutos que son los que perdurarán hasta 1714. Como ha señalado James Amelang, el nacimiento de este nuevo Brazo Militar cabe entenderlo como resultado de la creciente tensión entre la nobleza rural y el virrey. Fue eso lo que "animó a la clase alta a cerrar filas y formar un "gremio" único y permanente cuya tarea principal consistía en evitar otras usurpaciones de sus privilegios" ${ }^{15}$. De hecho, los mismos estatutos de 1602 ya lo afirmaban así y aseguraban que se instituían para que "les coses de dit col·legi sien governades y encaminades al be comú de tots lo del dit col·legi" y "per conservació de ses prerrogatives, inmunitats y privilegis" ${ }^{16}$.

Como recordaba Robres, la convocación del Brazo Militar «es universal a todos los que se encuentran en Barcelona del estamento y aunque no los llamen

12. Del Brazo Militar solo se ha conservado el Llibre de Deliberacions del Braç Militar. Contiene gran parte de la actividad del Brazo durante esos años, pero no toda. Se conserva en el Archivo de la Corona de Aragón, ACA, G-69. En adelante lo citaremos como LLDBM, reseñando solo el volumen y el folio.

13. Constitucions $i$ altres drets de Cathalunya: compilacions de 1495, 1588-1589, i 1704. Edición facsímil. Barcelona: Base, 2004, vol. II, p. 54.

14. Sobre la historia y los abaratares de este primer Brazo, cfr. SALVADOR, Felipe. "El Real Cuerpo de la Nobleza, antiguo Brazo Militar del Principado de Cataluña y condados de Rosellón y de Cerdaña". Hidalguía, 1957, 5, pp. 369-376. Una visión de conjunto de la institución también se encuentra en PI I ARImon, Andrés. Barcelona Antigua y Moderna. Barcelona: Librería Politécnica de Tomás Gorchs, 1854, vol. II, pp. 341-348. Otro autor de referencia es Armand de FuUVIÀ. Entre otras obras suyas cfr. "Precedents històrics del reial cos de la noblesa de Catalunya". Conferencia pronunciada en el Real Cuerpo de la Nobleza de Cataluña. Barcelona: 1991, p. 12.

15. Amelang, James. La Formación de una clase dirigente. Barcelona: Ariel, 1986, p. 98.

16. Archivo de la Corona de Aragón, G-225, Llibre Verd, fol. 3v. Un primer resumen de ellas, aunque parcial y pendiente de una versión definitiva, se puede encontrar en MARTí, Eduard. La classe dirigent..., pp. 75 y ss. 
pueden concurrir ${ }^{17}$. Esto otorgaba al Brazo una gran libertad de movimientos y un fuerte valor representativo, pues no había ningún filtro insaculatorio que impidiese a cualquier noble participar de las decisiones de su estamento en cualquier momento. El estudio de los libros de deliberaciones muestra que en ocasiones las reuniones del Brazo podían llegar a ser muy numerosas, como por ejemplo la del 3 de mayo de 1689 en que asistieron 153 personas para elegir los oficiales, o la del 3 de mayo de 1708 en la que asistieron 90 nobles diferentes ${ }^{18}$. El valor simbólico y moral que podían tener las decisiones que se tomasen en esos momentos era muy alto. Los estatutos de 1602 establecían la creación de una junta de oficiales formada por un presidente (llamado protector), un clavario, y seis consejeros (dos nobles, dos caballeros y dos ciudadanos honrados), a los que habría que añadir la figura del síndico, que habitualmente también era un noble. Esta organización aseguraba que todas las categorías nobiliarias estuvieran presentes en la dirección del estamento. La Junta de oficiales era el auténtico organismo directivo, pero para la gestión de asuntos complejos, el presidente podía designar otras juntas menores que les asesorasen.

Sin embargo, la característica más importante del Brazo Militar era que tanto sus oficiales como las decisiones acordadas en las reuniones plenarias, se tomaban, como decía Castellví, "a pluralidad de votos"19, habitualmente por mayoría simple. Esto otorgaba al estamento una gran independencia del poder real, ya que escapaba totalmente al control insaculario. Uno de los casos más conocidos es el de Francesc Sayol, que fue desinsaculado por Felipe V en febrero de 1705 por formar parte de la Conferencia de los Tres Comunes. A pesar de esta decisión, en mayo de ese año era escogido clavario del Estamento, de modo que continuó teniendo un papel activo en la vida política catalana ${ }^{20}$. Es esta libertad de movimientos lo que ayuda a entender el papel tan activo que tuvo el Brazo durante los primeros años del gobierno de Felipe V.

El prestigio que adquirió el Brazo durante la Guerra de Sucesión es el resultado de una larga evolución durante del siglo XVII. De esos años, lo que más destaca es el papel que tuvo el Estamento en la defensa del Principado, especialmente en la segunda mitad del siglo XVII, momento en el cual la frontera catalana estuvo continuamente bajo el peligro de los ataques franceses. Como nos lo recordó Morales Roca, el pueblo catalán «reconoció al estamento de los caballeros y gentilhombres su liderazgo en la defensa de la libertad y del bien común del Principado" ${ }^{21}$. La lectura del Libro de Deliberaciones del Brazo Militar nos muestra un estamento muy activo, especialmente durante los asedios de la ciudad. A parte

17. ROBRES. Historia..., p. 132.

18. LLDBM, vol. 4, fol. 531v. y vol. 8, fol. 492r.

19. Castellví, F. Narraciones..., vol. 3, p. 550.

20. LLDBM, vol. 7, fol. 299r.

21. Morales Roca, Francisco. "Privilegios nobiliarios...", 187. 
de los momentos en que el Monarca solicita la ayuda del $\mathrm{Brazo}^{22}$, encontramos que el Estamento suele ponerse al servicio del Consell de Cent para dirigir las escuadras de la coronela, las rondas nocturnas y ofrecer sus carrozas para el transporte de materiales ${ }^{23}$. Esta acción fue muy pronto reconocida por la Corona, que ya en 1678 agradecía "la finesa y fidelitat ab que la noblesa lo die 26 del corrent ha obrat respecte la invasió de las armas francesas contra esta ciutat ${ }^{24}$. Un buen ejemplo de esta actividad fue el asedio de 1691, en el que, a parte de la dirección de las escuadras y la defensa de las murallas, también ayudó a apagar los incendios y a transportar productos ${ }^{25}$. Este prestigio llegó en algunos momentos a superar a la misma Diputación, como sucedió en el asedio de 1697. En aquella ocasión los diputados optaron por abandonar la ciudad, mientras que el Brazo Militar permaneció hasta el final del asedio ${ }^{26}$. Pero no solo en los asedios tuvo un papel importante a nivel militar. En 1665 encontramos al Brazo colaborando en la vigilancia de las puertas de la ciudad para evitar la entrada de la peste declarada en Francia ${ }^{27}$, en 1690 hacía un donativo voluntario para el retorno de los prisioneros del enemigo ${ }^{28}$, y durante los años posteriores financió defensas del Principado como la de Tremp en 1692 o de Barcelona en 169329.

Toda esta actividad militar va a tener como consecuencia una mayor implicación del Estamento con el Consell de Cent, el cual valorará su sacrificio y valor. Tras el asedio de 1697 , la ciudad agradecía al Brazo su actuación, y por eso "sempre tindrà molt present esta merssè y procurarà totas los ocasions puga per demostrar tot affecte y estimació ${ }^{30}$. Este hecho era una manifestación más de que la base social que alimentaba al Brazo y a la Ciudad era esencialmente la misma. Como nos recordó James Amelang, la creación del Brazo Militar "Va confirmar la veu dominant de Barcelona dins del conjunt de l'aristocràcia catalana" ${ }^{31}$. Desde esta perspectiva se comprende mejor la sorprendente "unión de voluntades" que a nivel político tendrán el Consell de Cent y Brazo Militar durante los años de la Guerra de Sucesión ${ }^{32}$.

22. Cfr. LLDBM, G-69, vol. 3, fol. 242v.

23. Sobre la dirección de las escuadras, consultad la de 1684 (LLDBM, vol. 4, fol. 137) o la de 1694 (LLDBM, vol. 5, fol. 162). Sobre las carrozas, cfr. LLDBM, G-69, vol. 4, fol. 845r.

24. LLDBM, vol. 3, fol. 487r.

25. LLDBM, vol. 4. Fol. 774 r y ss.

26. Sobre el papel del Brazo durante el asedio de 1697 cfr. LLDBM, vol. 5, fols. 380r.- 511r.

27. LLDBM, vol. 3, fol. 132r.

28. LLDBM, vol. 4, fol. 795 r.

29. LLDBM, G-69, vol. IV, fol. 880r. LLDBM, G-69, vol. V, fol. 34v. 19 de junio de 1693.

30. Manual de Novells Ardits. Barcelona: Ayuntamiento de Barcelona, 1982-1975, vol. XXII, p. 215. De ahora en adelante lo citaremos como MNA.

31. Amelang, James. La formación..., p. 98.

32. Esta unión se puede ver en parte a través de la implicación que tuvieron estas dos instituciones en sacar adelante la Conferencia de los Tres Comunes. Cfr. MARTí, Eduard. La Conferencia de los Tres Comunes. Lleida: Milenio, 2008, pp. 87-132. 
La corona valoró positivamente toda la actuación del estamento. En 1679 reconocía que el Brazo Militar, "ha sabido granjear siempre en las ocasiones el real agrado de su magestad "33. En 1690 Carlos II les otorgaba el título de "fidelísimos" y en 1694 el tratamiento de embajadores a sus enviados a Corte ${ }^{34}$. Constatamos que hacia finales del siglo XVII el Brazo había adquirido un gran prestigio a los ojos de la monarquía, y se había convertido en un auténtico apoyo para la estabilidad de la región. Precisamente por eso, puede sorprender que en febrero de 1705, el virrey Velasco, después de recibir las peticiones del Estamento para perdonar a varios encarcelados, le criticase que este modo de actuar era "impropio de la innata fidelidad del Ilustre Brazo Militar" ${ }^{35}$. No era algo nuevo. Un año antes ya había advertido que, más que protestar, lo que debía hacer el Brazo era "cortar los miembros que estaban perdidos de aquel cuerpo tan noble para que no le infeccionase ${ }^{36}$. Esta visión, si bien con menos intensidad, era compartida en Madrid, al menos desde 1703. En marzo de ese año, un eclesiástico de la Corte consideraba que el Brazo tenía "molta altanería "37 por sus continuadas oposiciones contra las decisiones reales. ¿Qué había pasado para que se produjese un cambio de actitud tan drástico?

No es el objeto de las siguientes líneas hacer una historia de la Guerra de Sucesión en Catalunya durante los primeros años de Felipe $\mathrm{V}^{38}$. Lo que nos interesa es destacar el papel del Brazo Militar en este conflicto y los diferentes enfrentamientos que tuvo con la corona. Ya hemos comentado cómo en 1706 José Alós afirmaba que el Brazo se había atribuido la defensa de las Constituciones. El mismo autor proseguía diciendo que, guiados por su ejemplo, "por ser de personas ilustres y nobles sigue la ciudad en su Consejo de Ciento, que lo más se compone de la plebe, y los diputados han de hacer lo mismo, si no quieren ser mal vistos entre los del pueblo "39. Alós sugiere que fue el Brazo Militar el auténtico defensor de la constitucionalidad, frente a una Diputación y un Consell de Cent que en no pocas ocasiones acaban siguiendo sus demandas. ¿Exageraba? Bastantes años después, el autor anónimo de los Anales Consulares señalaba que durante el mes de febrero de 1701, en plena batalla por la aceptación del virrey Palma, el Brazo se esforzaba en "defensar las lleis de la Pàtria com a invigiladors

33. DGC, vol. VII, p. 343. 16 de enero de 1679.

34. MORALEs Roca, F. "Privilegios nobiliarios...", p. 178.

35. LLDBM, vol. 7, fol. 278r.

36. AHN, Estado, leg. 1605.

37. LLDBM, vol. 6, fol. 844r.

38. Evidentemente, la bibliografía sobre el tema es inabarcable. Quizá la obra que mejor lo estudie sea ALBAREDA, Joaquim. Els catalans $i$ Felip V, de la conspiració a la revolta, 1700-1705. Barcelona: Vicens Vives, 1993³. Otra obra de referencia a destacar es TORREs RiBé, Josep M. La Guerra de Successió i els setges de Barcelona. Barcelona: Rafael Dalmau, 1999.

39. GAY, Josep. El corregidor..., p. 755. 
de ella y que los diputats tiraban a destruirlas per fer obsequi als ministres ${ }^{40}$. El planteamiento es exactamente el mismo, a pesar que los dos autores pertenecían a bandos políticos netamente diferentes. ¿Casualidad?

\section{EL BRAZO MILITAR ENTRE 1700 Y 1703}

La defensa de la Constitucionalidad se va a manifestar con toda su radicalidad antes de la llegada de Felipe V. El 3 de noviembre de 1700 el virrey Darmstatd anunciaba a los Comunes la enfermedad de Carlos II y la designación del Cardenal Portocarrero como gobernador General. En seguida el Brazo Militar, junto al Consell de Cent, van a convocar una Conferencia de los Tres Comunes para ver la legalidad de la medida y, según Feliu de la Penya, enviar un correo al Cardenal en que se retrasaba la decisión de seguir la orden ${ }^{41}$. La situación se agravó unos días después con la muerte del monarca. La Corona enviaba una carta a los comunes donde se les informaba de la designación de Felip d'Anjou como heredero y la permanencia de Darmstatd como virrey. Esta segunda medida suponía una clara transgresión de la constitucionalidad, que exigía la aplicación de la vicerregia. Lo importante del hecho es que fue el Brazo el primero en tomar la iniciativa institucional: solicitó la apertura de la Conferencia de los Tres Comunes para decidir sobre la legalidad de la medida ${ }^{42}$, y consultó el tema con sus abogados. Estos deliberaron que no había que aceptar a Darmstatd como virrey y había que aplicar la vicerregia ${ }^{43}$. Después de muchas discusiones entre ellos ${ }^{44}$, la Conferencia se reunía y encargaba estos asuntos a los abogados de los tres comunes, los cuales aceptaron todas las indicaciones reales. Solo disintió Luis de Valencia, abogado del Brazo, pues consideraba que el virrey no podía ejercer la jurisdicción contenciosa hasta que el nuevo monarca no jurase las Constituciones ${ }^{45}$.

La Conferencia acordó seguir el parecer de los abogados y aconsejó a los comunes que hicieran lo mismo. La Diputación enseguida se adhirió a este parecer, pero no así la Ciudad y el Brazo Militar, que retrasaron mucho su toma de posición. Después de largas discusiones, la Ciudad cedía y decidía seguir también el consejo. El Brazo, muy a su pesar, tuvo que aceptar (inicialmente había mostrado su oposición), pero no renunció a presentar un memorial a la reina afirmando que "lo assentir no era perque los reparos no fossen rellevants, si sols per la quietut

40. Biblioteca de Catalunya, Anales Consulares. Manuscrito 173, vol. II, fol. 3v y 4r. De ahora en adelante lo citaremos como Anales Consulares, indicando el volumen y el folio.

41. Cfr. Feliu de la Penya. Anales..., p. 458. Cfr. También Mas, E. Diari..., fol. 2-3.

42. LLDBM, vol. 6, fol. 128r.

43. LLDBM, vol. 6, fol. $154 \mathrm{v}$.

44. Un estudio de este episodio se puede encontrar en MARTí, Eduard. "Conflictivitat institucional: La Conferència dels Comuns de novembre de 1700". Pedralbes, 2003, 23/2, pp. 209-232.

45. Cfr. Castellví, F. Narraciones..., pp. 224 y ss. 
pública " ${ }^{46}$. Lo más llamativo de este episodio es la actitud radical del Brazo Militar en la defensa del marco constitucional, una actitud mucho más exigente que la Diputación y el Consejo de Ciento, tradicionales defensores del marco legal catalán. De hecho, algún signo ya se podía percibir de ello con anterioridad. Así, por ejemplo, encontramos, que en 1696 el Brazo acordaba defender a un soldado y que "en cas lo molt il·lustre consistori [de los Diputados] no obrés cosa, la molt il·lustre Junta continuás aquelles diligencias li aparexerà " ${ }^{47}$.

Pero como es conocido, lo sucedido en noviembre fue solo la primera parte de un duro conflicto entre la Diputación por un lado, y el Brazo Militar y la Ciudad por otro, sobre la aplicación de la vicerregia y la ejecución de la jurisdicción contenciosa por parte de la Real Audiencia. A ello hay que añadir la negativa que en febrero de 1701 ejercieron el Brazo y la Ciudad a la aceptación del Conde de Palma como nuevo virrey de Cataluña. El episodio, bien estudiado por Eva Serra ${ }^{48}$, cabe entenderlo como una auténtica, "tarja de presentació sobiranista envers el nou rei». La autora concluye que fue el Brazo Militar el que tuvo la actitud más radical, "arrossegant" detrás suyo a la misma Ciudad de Barcelona ${ }^{49}$. No es nuestro objetivo explicar este conflicto, pero quisiéramos destacar dos o tres elementos significativos. En primer lugar, que la actitud reticente del Brazo, se percibió desde el inicio, al negarse en diciembre a entregar sus credenciales al embajador que la Diputación iba a enviar a Madrid para dar la bienvenida a Felipe $\mathrm{V}^{50}$. Pero no solo eso, en enero el Brazo apoyará las protestas y el memorial que el Consell de Cent hizo llegar a la capital a través de Francisco de Miquel, su embajador ${ }^{51}$. Cuando este sea conminado a abandonar la capital, el Brazo enviará un nuevo embajador (Felip Ferran) que junto con el de Ciudad (Pere Ribes) tenían la misión de hacer llegar al rey su oposición al Conde de Palma ${ }^{52}$. La actitud tan agresiva del Brazo causó gran sorpresa en Madrid. El 9 de abril de 1701 el Consejo de Aragón pedía a Palma un informe sobre la actuación del Estamento en esta situación pues "hasta ahora no se ha sabido qué motivo, derecho e interés tuvo el Brazo Militar para coadyuntar los procedimientos de la ciudad en su desobediencia,"53. Algo de esto ya lo percibió el agente de la Diputación Joan de Gensana, que el 6 de febrero informaba a los diputados de cómo la mayor parte de los miembros del Consejo

46. MAS, E. Diari..., fol. 4. El memorial se encuentra en LLDBM, vol. 6, fols. 282r-295v.

47. LLDBM, vol. 6, fol. $234 \mathrm{r}$.

48. SERRA, E. "Voluntat de sobirana...”. Respecto a las versiones de los contemporáneos cfr. FELIU DE la PenYa. Anales..., vol. 3, pp. 462-473; Castellví, F. Narraciones..., vol. I, pp. 210 y ss.; Biblioteca de l'IUHJVV, Publica Notícia del acierto... Diputació i Catalunya, Tomo III.

49. SERra, Eva. "Voluntat de sobirania...”, p. 165.

50. Castellví, Francesc. Narraciones..., vol. I, p. 249.

51. MAS, E. Dietari..., fol. 8.

52. LLDBM, vol. 6, fol. 266r.

53. AHN, Consejo, Legajo 2377 (Cartas misivas). 
de Aragón y de Estado "han avorrit y avorreixen la ceguedad dels altres dos comuns que han obligat a Sa Magestat a fer eixir al senyor D. Francisco de Miquel ${ }^{54}$.

La "beligerancia" del Brazo no disminuyó con el paso del tiempo. Con el inicio de las Cortes de 1701 se acentuó. Es conocido el importante papel que tuvo el Estamento Militar durante ellas, los conflictos que se produjeron por la presidencia de Estamento antes de iniciarse ${ }^{55}$ y la trascendencia del disentimiento general presentado por Pere Torrelles hasta que no se devolviese el control insaculatorio ${ }^{56}$. Aquí hay que hacer hincapié en el hecho que sea precisamente el Brazo Militar el máximo defensor del retorno de esta prerrogativa, cuando en su institución no había insaculación. Ello ya nos muestra que la actitud del Brazo no estaba guiada por intereses puramente estamentales. Lo significativo de estas Cortes, es que el Brazo fue el único común que protestó reiteradamente por su prorrogación (9 y 20 de septiembre), lo cual causó una fuerte división interna ${ }^{57}$. A ello habría que añadir que, una vez iniciadas, el Brazo también protestó por la habilitación de sus miembros ${ }^{58}$. En este y otros aspectos se constata la actitud de un Estamento netamente más beligerante que el resto de los comunes. Quizá sea eso lo que explique en parte la visión negativa que tiene Robres de la actitud del Brazo y de las mercedes que le concedió Felipe $\mathrm{V}$ al finalizar, las cuales «acrecentaron a los quejosos y no ganaron el afecto a los beneficiados " ${ }^{59}$.

Poco después de la finalización de las Cortes, los problemas con la corona se renuevan, esta vez por la formación del Tribunal de Greuges. Los tres comunes salieron en defensa de Jeroni Magarola, que era el juez al que le correspondía el cargo, pero el Brazo dio un paso más allá en sus demanda, y facultó a sus oficiales para "fer ambaixades al rei nostre Senyor, y als altres senyors, tenir conferències y fer ambaixades als altres comuns ${ }^{60}$. Sin embargo, el conflicto que al que dedicó más esfuerzos se produce el 15 de mayo de 1702 cuando Felipe V informaba de la Nueva Planta de Gobierno de la Corona, en la que dejaba como gobernador al Cardenal Portocarrero (desde mayo) y posteriormente a la Reina (desde julio). El Brazo otorgaba poder a una Junta para tratar el tema ${ }^{61}$, convocaba a sus abogados y rápidamente solicita conferencia a los otros dos comunes para debatir la lega-

54. Citado por Simón, Antoni. De $1640 \ldots$, p. 253

55. Sobre el conflicto de la precedencia hay numerosas referencias. A modo de ejemplo cfr. MAs, E. Diari..., p. 45 y ss. y RoBRes. Historia..., p.77. y ss.

56. Sobre las Cortes de 1701 se ha escrito mucho. A manera orientativa BARTOLí, Jaume. "La Cort de 1701-1702: un camí truncat". Recerques, 1979, 9, pp. 57-75; AlbarEDA, Joaquín. "Les Corts de 1701-1702 i de 1705-1706. La represa del constitucionalisme". En Constitucions, capitols $i$ actes de cort 1701-1702 i 1705-1706. Barcelona: Parlament de Catalunya, pp. XVII-XLV. Habría que añadir también las numerosas referencias de Francisco Castellví, Emanuel Mas y Narcís Feliu de la PenYa.

57. LLDBM, vol. 6. fols. 331r-339v.

58. Más. E. Diari..., p. 55.

59. ROBRES. Historia..., p. 95.

60. LLDBM, vol. 6, fol. 359r. Cfr. DGC. Vol. X, 18 de febrero de 1702

61. LLDBM, vol. 6, fol. 380v. 
lidad de la medida y la necesidad de oponerse a ella. Tanto el Consell de Cent como la Diputación rechazaron la opción de tener conferencias, pues ambos consideraron que las decisiones eran constitucionales ${ }^{62}$. Pero el Brazo no se rindió y el 27 de julio redactaba un memorial para Felipe V donde exponía sus razones para la negativa ${ }^{63}$. A lo largo de los meses posteriores hasta bien entrado el otoño, el Brazo presionó fuertemente a la Diputación para que saliese en defensa del marco constitucional, incluyendo varias reuniones de los abogados de ambos comunes, los cuales reafirmaron la legalidad de la medida ${ }^{64}$. El Estamento envió numerosas cartas en solitario a la Corte. Su presión fue tan grande, que el 25 de noviembre el Duque de Cesa se excusó de entregar las cartas del Brazo al monarca porque «su contenido es de materia tan reprobable y grave y en nada semejante a las que en otras ocasiones han ido por mis manos" ${ }^{65}$. Pero este contratiempo no amedrentó al Brazo Militar, que dos días después volvía atacar a los Diputados por su inactividad y les amenazaba con denunciarles en la próxima visita por no defender las constituciones $^{66}$. Como recuerda el autor de los Anales Consulares, "el Braç Militar fou el que més se esmerà en esta dependencia "67 y el mismo Conde de Robres se sorprende de la actitud del Brazo, el cual "se resistió, de suerte que aun juzgo que no se han registrado en él las mercedes de Cortes que por la ausencia de su real esposo firmó la Princesa" "68. La actitud tan beligerante del Brazo nos puede sorprender, pero lo cierto es que los dolores de cabeza para la Corona no habían hecho más que empezar.

\section{LA DEFENSA DE ARNALD JÄGER Y SUS CONSECUENCIAS}

Aún estaba batallando el Brazo su oposición a la Nueva Planta y al gobierno de la Reina, cuando estalló el conflicto por la expulsión de ciudadano honrado de origen holandés Arnald Jäger a finales de octubre de $1702^{69}$. La decisión atentaba contra los privilegios del ciudadano honrado y el Brazo Militar y el Consell de Cent no dudaron un instante en salir en su defensa. Una vez más se percibe en este conflicto el liderazgo del Estamento de la nobleza. Robres recuerda perfecta-

62. Cfr. Archivo histórico de la Ciudad de Barcelona, Libro de Deliberaciones del Consell de Cent, 1B, II, 211, fol. 170r. De ahora en adelante lo citaremos como LLDCC indicando el volumen y el folio.

63. LLDBM, vol. 6, fol. 418r.

64. DGC, vol. X, p. 109.

65. LLDBM, vol. 6, fol. 545 r.

66. LLDBM vol. 6, fol. 551r.

67. Anales Consulares, vol. II, fol. 23v.

68. RoBRes. Historia..., p. 123.

69. Una explicación del conflicto se puede seguir en MARTí, Eduard. La conferencia..., pp. 96-106. También en AlbaredA, Joaquim. Els catalans..., pp. 90-110. Entre los memorialistas que recogen datos interesantes Cfr. CASTEllví, F. Narraciones..., vol. I, pp. 363 y ss. y Robres. Historia..., pp. 128 y ss. 
mente que la Ciudad acordó "apoyar al Brazo Militar, dando facultad a los concelleres para obrar de acuerdo con él y prevenir y disponer todo lo necesario a fin de que no fuesen holladas las Constituciones del País ${ }^{70}$. Guiados por la Conferencia, los dos comunes no escatimaron recursos en su objetivo. Primero decidieron defenderle a través de métodos judiciales que se visualizaron en los repetidos intentos por abrir del Tribunal de Contrafacciones (noviembre y diciembre de 1702 y primavera de 1703). Pero ante la lentitud de ellos, se decidió acudir también a los métodos extrajudiciales, ya fuera a través de cartas y representaciones al Rey y a diferentes miembros de la Corte, o el envío de un embajador especial a Madrid. El conflicto conllevó un duro enfrentamiento con la Corona y al final Felipe V tuvo que claudicar. En julio de 1703 revocaba el decreto ${ }^{71}$. Como recordaba un memorial borbónico "ganaron ellos, no por vía justicia, sino que a fuerza de requerimientos y de casi un sin número de replicas que hizieron" ${ }^{72}$. La concesión de Felipe V cabe entenderla porque, como decía otro memorialista, el rey "no se consideraba muy seguro de la fidelidad de los catalanes ${ }^{73}$. Detrás de este conflicto se esconden un debate mucho más profundo y de gran trascendencia política: la apropiación por parte del Brazo Militar de la defensa de las Constituciones frente a una Diputación cada vez más inoperante. Ello implicó un duro enfrentamiento del Brazo Militar con la Diputación y, simultáneamente, con la Corte, debido a sus insistentes demandas. Es precisamente en estos dos aspectos en los que quisiéramos detenernos.

Ya desde el principio la Diputación mantuvo una actitud ambigua y puso dificultades para la apertura del Tribunal del Contrafacciones. Muy significativamente, en diciembre, los dos comunes enviaban una representación al Rey exigiendo la supresión del decreto, mientras que la Diputación enviaba otra carta en un tono notablemente menos agresivo ${ }^{74}$. A lo largo de los meses posteriores la tensión con la Diputación fue en aumento. En febrero la Conferencia denunciaba que "se experimenta alguna lentitut i omissió en lo molt il·lustre i fidelíssim consistori [de la Diputación], ${ }^{75}$ y por esta razón, por consejo suyo, la Ciudad comunicó que denunciaría a los diputados en la próxima visita ${ }^{76}$. La actitud ambigua de la Diputación continuó durante la primavera. El 7 de abril de 1703, Josep Duran

70. RoBRes. Historia..., p. 130. La referencia la recoge Robres en la nota a pie de página.

71. Castellví, F. Narraciones..., vol. I, p. 415; Feliu de la PenYa. Anales..., vol. III, p. 513; Mas, E. Diari..., p. 279.

72. FERNÁNDEZ, M. "Espionatge borbònic a la Barcelona austriacista. Un informe de l'any 1706". En Actes del I Congrés d'Història Moderna de Catalunya. Barcelona: Diputació de Barcelona, 1984, pp. 243-252. La cita está en la p. 245.

73. Alabrús, Rosa. Escrits polítics del segle XVIII. Vic: Eumo, 2007, vol. 4, p. 169

74. LLDBM, G-69, vol. VI. fol. 713v. Cfr. también CASTEllví, F. Narraciones..., vol. I, p. 364.

75. Archivo Histórico Municipal de Barcelona, Dietario de la Conferencia, Corts, XVI-89. Microfilm, 119, 13 de febrero de 1703. De ahora en adelante DC.

76. MAS, E. Diari..., p. 237. 
ironizaba sobre el representante de la Generalitat en la Corte: "bon subjecte de agent tenen los senyors de la Diputació y crech sel deuen haver fet a mida de son gust, suposat que a més de no moure's un instant de casa Marimon.... ${ }^{77}$. Por esta razón, erigiéndose en portavoz de la defensa de la constitucionalidad, el Estamento pedía al embajador que informase con detalle de la actuación del representante de la Generalitat, "per a que en vista de ella ab més fonament se puga solicitar lo remey" ${ }^{78}$. Lo cierto, como constatan los Anales Consulares, a los diputados "lo poble y la noblesa los donavan temor ${ }^{79}$.

Es en esta situación en que la Corona decidió actuar y el 15 de marzo la Real Audiencia imponía la conocida multa al Protector para que retirase sus instancias en el Tribunal de Contrafacciones ${ }^{80}$. La reacción de la nobleza, que había sido el primer objetivo de la Real Audiencia ${ }^{81}$, fue enviar a Josep Duran a la Corte, lo cual se hizo por consejo de la Conferencia y contó con el apoyo incondicional de la Ciudad, que también lo asumió como propio ${ }^{82}$. El libro de Deliberaciones del Brazo recoge con todo detalle el desarrollo de las gestiones que hizo Duran en Madrid, el cual escribió más de 10 cartas al Brazo entre marzo y julio de 1703. Allí se percibe la audacia y la agresividad del Estamento en la defensa de la Constitucionalidad. En la misma representación del 18 de marzo, mostraba cómo la nobleza, "que havent sabut derramar tant sanch per a mantenirse y conservar tot lo Principat en lo suau domini de sos reys y senyors naturals, se troba ultrajada per los ministres de aquella Real Audiencia calumniantla de perturbadora de la pública quietud, essent així que sols dits ministres son los que la perturban" ${ }^{83}$. En mayo tuvo ocasión de hablar personalmente con Felipe V y en esa situación no dudó en transmitir que "tres hombres que por otro lado apellido llamaban la cuarteta querían echar a perder el Principado de Cataluña, poniendo en descrédito a tan leales y fieles vasallos y en desconfianza a su Magestat, asegurando a su Magestd que no miran a otro fin, que el de su propio interés". Por esta razón solicitaba al monarca que se informase bien de lo que sucedía en el Principado y que "cuando no sea verdad mándeme Vuestra Magestad cortar la cabeza, que mi único fin sólo es el de preciarme de buen vasallo» ${ }^{84}$. La declaración causó mucho revuelo en la Corte,

77. LLDBM, vol. 6, fol. 844 .

78. LLDBM, vol. 6, fol. 844r.

79. Anales Consulares, vol. II, fol. 28v

80. Feliu de la Penya, N. Anales..., vol. III, p. 512

81. Este episodio ha sido ampliamente narrado por los memorialistas, como MAs, E. Diari..., pp. 246 y ss. y Robres. Historia..., pp. 132-133.

82. LLDBM, vol. 6, fol. 785r i ss. El libro de deliberaciones recoge con todo detalle el envío de Josep Duran, con la Representación del Brazo para el Rey. Allí se dice explícitamente que la finalidad de su misión es conseguir la derogación del decreto de expulsión de Jäger. Cfr. Castellví, F. Narraciones..., vol. I, p. 414, y DC 21 de marzo 1703.

83. LLDBM, vol. 6, fol. 286r.

84. LLDBM, vol. 6, fol. 881v. 
especialmente por la "ruda energía" de Duran, pero sirvió para mostrar el fuerte posicionamiento del Brazo en la causa de Jäger, lo que causó gran admiración.

Estas y otras actuaciones de Duran sirvieron para prestigiar notablemente al Estamento Militar, hasta el punto que en un encuentro con Felipe V, el monarca le dijo al duque de Gandía "aquí está Cataluña", señalando al embajador del Estamento Militar ${ }^{85}$. De este modo se percibe cómo progresivamente, a los ojos de gran parte de la Corte, el Brazo estaba asumiendo la representación de todo el Principado. Las divisiones eran muy grandes. En mayo Duran denunciaba "la depravada intenció d'alguns destos ministres del Consell de Aragó, abrigats de la Capa de algú que era superior ${ }^{86}$. El embajador va informando del parecer de los diferentes miembros, tanto de los favorables como los que no, pero la derogación del decreto no llegaba, por lo que el Brazo se planteó la necesidad de que el embajador retornase a Barcelona. En este contexto, a principios de junio, el marqués de Rocha insistió a Duran que se quedase, pues todo parecía que acabaría bien. Sin embargo, la razón de fondo era el temor que "si jo arribava a eixa ciutat sens despatx podría resultar algún incident de conseqüència", lo cual es indicativo del temor que generaba el conflicto en el gobierno de Madrid, especialmente por la influencia que podría ejercer el Brazo sobre la plebe ${ }^{87}$.

Todas estas medidas dieron resultado y a principios de junio se recibía en Barcelona la derogación del decreto de expulsión de Arnald Jäger ${ }^{88}$. La decisión suponía una clara victoria de los dos comunes, pero especialmente del Brazo Militar, cuya agresividad había causado una gran impresión en la Corte. Así lo comunicaba Josep Duran al Estamento en abril de 1703: "crech lo fa més cas lo sentiment que Vostra Senyoria te en est fet que en la quiexa dels tres comuns en ordre a la conservació de les constitucions" $" 89$. No exageraba. El conflicto había servido para que en Madrid tuvieran claro, como decía el mismo Estamento en mayo, que "lo únic Blanch amb ha dirigit y dirigeix lo Braç Militar" era la defensa de las Constituciones ${ }^{90}$. El liderazgo del Brazo en esa coyuntura era evidente y el virrey Palma lo notó en sus propias carnes. Cuando en diciembre de 1702 se tuvo que renovar su mandato, los Anales Consulares recogen la fuerte oposición que tuvo de los miembros "del Braç Militar y de la Conferència dels Tres Comuns, que l'exclö̈en per contrafactor "' ${ }^{91}$. A lo largo de los meses siguientes, la agresividad del Brazo no hará sino aumentar.

85. LLDBM, vol. 6, fol. 843r.

86. LLDBM, vol. 6, fol. 885r.

87. LLDBM, vol. 6, fol. 901v.

88. Castellví, F. Narraciones..., vol. I, p. 415; Feliu de la PenYa, N. Anales..., vol. III, p. 513.

89. LLDBM, vol. 6, fol. 842v.

90. LLDBM, vol. 6, fol. 877v.

91. Anales consulares, vol. II, p. 26v. 


\section{HACIA UN ENFRENTAMIENTO CONTINUADO}

En marzo y mayo de 1703 el Estamento había tenido una parte activa en los conflictos que se produjeron por la configuración de los miembros del Tribunal de Greuges y los nuevos estatutos sobre el sueldo de los notarios. En ambos, guiados por la Conferencia, se hicieron llegar representaciones al Rey a través de Josep Duran ${ }^{92}$. La tensión aumentó con el conflicto por las cátedras de filosofía de la universidad y la inspección del correo. En el primer episodio, la nobleza dio pleno apoyo a la Ciudad, a pesar que era un tema que no afectaba directamente a sus intereses ${ }^{93}$. Robres muestra su sorpresa por la reacción del Brazo y considera que se opuso seguramente para "irritar al pueblo contra el gobierno" ${ }^{94}$. El hecho es que nuevamente el Brazo escribió a Felipe $\mathrm{V}^{95}$. Ahora bien, el conflicto que generó una mayor crispación fue la apertura de las cartas personales de destacados miembros de la nobleza. Entre esas cartas se constató que no estaban las que Josep Duran debía enviar al Estamento ${ }^{96}$. Como decía el Protector, la actuación de la Real Audiencia había generado un "desconsuelo fins vuy ni vist ni ohit" ${ }^{97}$, y Emanuel Mas apuntaba que "aparegué cosa molt nova e inusitada y en grave dany y prejudici del públic y particular de esta ciutat, ${ }^{98}$. Brazo y Consejo de Ciento decidían hacer una nueva representación al Rey ${ }^{99}$ y denunciaron que estas inspecciones se hacían "sin excepción de distinción de personas de todos los estados" El virrey Palma se disculpaba, pero no nos engañemos, la inspección de las cartas del Brazo era un signo claro de la creciente desconfianza que empezaba a nacer en la Corte. La "ruda energía" de Duran estaba teniendo sus consecuencias.

La tensión aumentó con el decreto de modificación del testamento de Carlos II, para asegurar que, en caso de muerte de Felipe V, la sucesión fuera a la línea francesa y no austríaca ${ }^{101}$. El Brazo y el resto de los Comunes resistieron fuertemente la orden, a pesar de que, como reconocía Robres, se desconocía «el privilegio a que se oponía esta obediencia y quizás los mismos que la resistieron

92. LLDBM, vol. 6, fols. 922r.-924r. Sobre estos episodios, cfr. MARTí, Eduard. La Conferencia..., pp. 109-110.

93. Sobre el conflicto, a parte de las versiones de Castellví y Robres, es de referencia ineludible el clásico de SOLDEvila, Ferran. Barcelona sense universitat i la restauració de la universitat de Barcelona. 1714-1838. Barcelona: Universitat de Barcelona, 1938). Recientemente Benet Oliva ha aportado datos relevantes en "Conflicte ideològic i control de la Universitat. La "verdad triunfante" de Narcís Feliu de la Penya (1682)". Recerques, 2002, 44, pp. 181-198.

94. ROBRES, Historia..., p. 160.

95. La representación la enviaban la Ciudad y Brazo. Cfr. LLDCC, 1B, II, 212, fol. 230v.

96. Cfr. LLDBM, vol. 6, fol. 929v.

97. LLDBM, vol. 6, fol. 931r.

98. MAS. E. Diari..., p. 296.

99. LLDBM, vol. 6, fol. $942 \mathrm{v}$.

100. LLDBM, vol. 6, fol. 938r.

101. Cfr. Feliu de la Penya. Anales..., vol. III, pp. 515 y ss.; Castellví, F. Narraciones..., vol. I, pp. 417 y ss. y MARTí, Eduard. La Conferencia..., pp. 212-214. 
lo ignoraban también "102. A lo largo de los meses siguientes tanto Palma como Velasco, que entró como virrey a partir de 1704, presionó enormemente a los comunes para que cambiasen de opinión. Las gestiones solo fueron eficaces con la Diputación, que en junio de 1704 decidía obedecer el decreto. Brazo y Ciudad se mantuvieron firmes en su oposición ${ }^{103}$. Lógicamente no pasó por alto a la Corte esta repetida desobediencia. En enero de 1705, se decidía desinsacular a "a los abogados del Braço Militar que escribieron diferentes papeles y aconsexaron lo contrario [de obedecer la orden real], ${ }^{104}$. Las autoridades reales, fueron tomando conciencia poco a poco del papel preponderante que estaba ejerciendo el Brazo en esta nueva coyuntura política.

El fracasado asedio de 1704 pareció restablecer la buena sintonía entre el Estamento y la Corona ${ }^{105}$. Es de sobra conocida la actuación que tuvieron los tres comunes esos días ${ }^{106}$. El Brazo volvió a capitanear la coronela, dirigió las escuadras, hizo rondas nocturnas para mantener la quietud pública y escribió a los nobles del Principado solicitando ayuda ${ }^{107}$. Todo ello le valió el reconocimiento del Rey y de diferentes miembros de la Corte, que a lo largo de los meses de junio y julio le felicitaron por su actuación ${ }^{108}$. Pero no pasó mucho tiempo para ver que todo era un espejismo. Poco después el virrey Velasco empezó una campaña de encarcelamientos injustificados. Cuando estos afectaron a Ramon Vilana Perlas y Narcís Feliu de la Penya la reacción del Brazo fue fulminante ${ }^{109}$. Además de protestar a Velasco, decidió escribir una representación al Rey de común acuerdo con el Consejo de Ciento, mientras que los diputados, "sorprendidos del temor, no quisieron acompañar la representación "110. El Brazo exigía al virrey la liberación de los presos, pues de no hacerlo se "podrían dificultar la fidelitat dels sujetos que espera lo Bras ha de lograr lo Rey contra los enemichs" ${ }^{111}$. Pero Velasco no se amedrentó y escribió a Madrid solicitando que no se atendiesen las peticiones de indulto de los dos comunes ${ }^{112}$. En este contexto de crispación creciente, el conflicto por Honorat

102. RoBres. Historia..., p. 155.

103. DGC, vol. X, p. 503-504. Cfr. también FERnÁNDEZ y CERVANTES, M. "Espionatge borbònic....", p. 246.

104. AHN, Consejo, Libro 2377.

105. Sobre el desarrollo del asedio, cfr. especialmente los relatos de CASTELLVí, F. Narraciones..., vol. I, pp. 446-451 y Mas, E. Diari..., pp. 393-407. Tanto el marqués de San Felipe como el conde de Robres también aportan datos relevantes. Entre los historiadores Cfr. PORTA, Antoni. La victòria catalana de 1705. Barcelona: Pòrtic, 1984, pp. 217-230 y TORRAS RiBÉ, Josep. La guerra..., pp. 91-99.

106. MARTí, Eduard. La Conferencia..., pp. 120-122.

107. La mayoría de estas decisiones las hizo siguiendo el consejo de la Conferencia. Cfr. LLDBM, G-69, vol. VII, fol. 12r.

108. LLDBM, G-69, vol. 7, fols. 79v. y ss. Cfr. también LLDCC, 213, fol. 238v.

109. Cfr. AHN, Estado, leg. 1605.

110. Castellví, F. Narraciones..., vol. I, p. 464. Cfr. LLDBM, vol. 7, fol. 123r.

111. LLDBM, vol. 7. fol. 119v.

112. AHN, Estado, leg. 1605. 
Pallejà que estalló unas semanas después, solo sirvió para avivar el fuego ${ }^{113}$. El 5 de julio el Consejo de Ciento pedía el apoyo del Brazo en sus demandas, el cual, siguiendo la misma línea de actuación que los consellers, acordaba excluir a Pallejà de las reuniones de Estamento ${ }^{114}$. Una vez más la Diputación se quedó rezagada y no siguió el ejemplo de la nobleza ${ }^{115}$.

El cúmulo de constituciones transgredidas en los últimos años era enorme. A mediados de agosto, la Conferencia redactaba un largo memorial a Felipe V con más de 10 conflictos pendientes de solución. Se propuso que el Consejo de Ciento la enviara, pero para que fuera eficaz era necesario acompañarlas de cartas recomendatorias del Brazo Militar. La misma conferencia redactó las 14 misivas. Entre los destinatarios estaban la reina, los duques de Medinasidonia, Cardona, Montalto y Cesa así como el marqués de Benavente, de Leganés y Antonio Ubi$1 l a^{116}$. El hecho en sí mismo es indicativo del peso y prestigio que había adquirido el Brazo y que se había convertido en una pieza clave para hacer llegar con éxito instancias a las manos del Rey.

\section{LA CORONA REACCIONA}

A los ojos de una parte importante de la Corte, el Brazo y la Ciudad se habían excedido en su celo, por esta razón, a mediados de diciembre Velasco ordenó el encarcelamiento de varios miembros del Consell de Cent ${ }^{117}$. En febrero de 1705 le tocó el turno a algunos jueces de la Real Audiencia, a los abogados de la nobleza y a los miembros de la Conferencia de los Tres comunes y la misma conferencia ${ }^{118}$. A lo largo de estos meses de dura represión ${ }^{119}$, el Brazo Militar se mantuvo firme en su defensa de la constitucionalidad y el 9 de enero exigía al virrey la liberación de los encarcelados ${ }^{120}$ a la vez que nombraba una junta para conseguir este objetivo y escribir al rey ${ }^{121}$. El 7 de febrero, después de la segunda oleada represiva, se volvía a presionar a Velasco. Esta vez la reacción del virrey fue muy agresiva

113. Sobre este conflicto cfr. las memorias publicadas por AlBareda Joaquin. Política, religió $i$ vida quotidiana en temps de guerra (1705-1714). Vic: Eumo, 2001. Cfr. también MAs, E. Diari..., pp. 429-500. Resulta también interesante un memorial de Pallejà que se conserva en Archivo General de Simancas, Estado, leg. 7838.

114. LLDBM, vol. 7, fol. 160 y ss.; 177r. La exclusión de Pallejà está en el fol. 180r.

115. Cfr. LLDBM, vol. 7, fol. 173r.

116. LLDBM, vol. 7, fol. 243r.

117. MAS, E. Diari..., pp. 500-503.

118. Castellví, F. Narraciones..., vol. I, pp. 464 y 469; DGC, vol. X, pp. 572 y ss. El decreto de la supresión de la Conferencia se encuentra entre otros sitios en MNA, vol. XXV, p. 8.

119. Lo sucedido está muy bien recogido en MAs, E. Diari..., pp. 500-520. Cfr. también el relato de Feliu de la Penya, N. Anales..., vol. III, fols. 528-530. Respecto a los historiadores cfr. Albareda, Joaquim. Els catalans..., pp. 153-155 y 159-167.

120. LLDBM, vol. 7, fol. 275 v.

121. LLDBM, vol. 7, fol. 275v. La Junta escribió al rey al día siguiente. Cfr. LLDBM, fol. 276r. 
y criticó al Estamento que se atreviera a pedir que "no castigara a los que habían faltado a la fidelidad que devían a su Rey, ahora me pide que perdone a los que no han obedecido a sus órdenes [...]. Uno y otro muy impropio de la innata fidelidad del Ilustre Braço" ${ }^{122}$. La indignación de la nobleza fue tal que decidió escribir al monarca. Después de mostrar la fidelidad mostrada durante el asedio de 1704, criticaba "el poco agrado, aceptación y agasajo con que el lugarteniente de vuestra magestad trata al Braço (jamás experimentado en sus antecesores) y queda toda la nobleza catalana mortificada y inconsolable ${ }^{123}$. El día siguiente, el Brazo todavía se atrevía a cuestionar la validez del decreto de supresión de la Conferencia, cosa que parece que no hicieron el resto de comunes ${ }^{124}$.

A partir de mediados de febrero la documentación del Estamento escasea. Parece claro que fue en ese momento cuando se creó una Junta Secreta de los comunes para coordinar la liberación de los presos. Tanto Castellví como los Anales Consulares hablan de ella ${ }^{125}$. Fue esta junta la que aconsejó el envío de Pau Ignasi Dalmasses y Faust de Potau a Madrid para conseguir la liberación de los presos. Los dos embajadores iban en nombre de la Ciudad pero con el beneplácito explícito del Brazo Militar ${ }^{126}$. Siguiendo la versión de los Anales Consulares, constatamos que durante los meses siguientes Velasco continuó con la política de castigos, "Oprimint a diferents presos sens ferlos procés per no trovar testimonis" 127. Esto llevó a "la ciudad y Brazo Militar a unir sus instancias al Virrey para acallar las repetidas quejas y suavizar la general aflicción", lo que se manifestó en la representación del 10 de abril ${ }^{128}$. Es en este contexto que se produjeron los levantamientos en la plana de Vic que, como recuerda Robres, hubo "dictamen universal de que eran sostenidos de mucha nobleza " ${ }^{129}$.

En mayo se renovaron los oficiales del Brazo y se creaba una nueva junta con amplias facultades para la defensa de las Constituciones ${ }^{130}$. Pocos días después estallaba el conflicto por las fortificaciones que estaba haciendo Velasco en la ciudad, con las que "manifestó sus sospechas y su resolución de molestar a los

122. LLDBM, vol. 7, fols. 277v.-278r.

123. LLDBM, vol. 7, fols. 279v.-280r.

124. LLDBM, vol. 7, fol. 280r.

125. Cfr. Castellví, F. Narraciones..., vol. I, p. 494; Anales Consulares vol. II, fol. 38r.

126. Cfr. Castellví, F. Narraciones..., vol. I, p. 494. El LlDCC muestra cómo algunas de las representaciones de los comunes se enviaron a través de Pau Igansi Dalmases. LLDCC, 1B, II, 214. fols. 79v. y 80r. Sobre la historia de esta embajada cfr. SoldEvila, Ferran. "La presó de Pau Ignasi Dalmases i Ros, enviat de la ciutat de Barcelona a Felip V (1705)". Homenatge a Antoni Rubió i Lluch. Barcelona: Institut d'Estudis Catalans, 1936, pp. 481-498.

127. Anales Consulares, vol. II, p. 38r.

128. Castellví, F. Vol. I, p. 495. Una vez más, la Diputación se quedó atrás y no apoyó esta representación.

129. RoBres. Historia..., p. 236.

130. LLDBM, vol. 7, fol. 300r. 
naturales" ${ }^{131}$. Como recordaban los Anales Consulares, Velasco puso "troneras y pesas de artillería apuntadas envers la ciutat en cada portal y bocacalle "132. La reacción de Estamento fue hacer una nueva representación al Felipe V y denunciar que las defensas «amenazan a esta ciudad y sus moradores, cosa que en ningún tiempo prácticas, infiriéndose de ellas la desconfianza en que vive el lugarteniente de Vuestra Magestad de estos naturales y principalmente de la nobleza [...]. Y que algunos de los reales ministros procuran por todos los medios reducir a servidumbre a estos sus fidelísimos vasallos ${ }^{133}$. La representación era un duro golpe para Velasco y mostraba, una vez más, que el Brazo no dudó en denunciar siempre los abusos del virrey en el rompimiento de las Constituciones.

La sorpresa llegó cuando el marqués de Mejorada rechazaba presentar al Rey la representación y sugería al Estamento que lo hiciera a través del Consejo de Aragón ${ }^{134}$. Algo había cambiado en la Corte, pues el agente del Brazo en Madrid informaba de que el Duque de Montalto le había dicho lo mismo aunque cogió la carta y el de Medinasidonia confesaba "que tenía orden de SM de no recibir semejantes cartas y con sentimiento no poder servir a V.S como ha hecho hasta aquí" ${ }^{135}$. La razón de este cambio de actitud se halla en una carta que unos días antes, el 23 de mayo, Velasco había enviado Felipe V. En ella le informaba que "estos comunes, cuando quieren hacer representaciones opuestas a la razón, [...] se valen de algunos de los señores de la primera suposición de esa corte a quien remiten sus cartas con súplicas que las ponga en manos de su magestad. Y de quien para este fin efecto se han valido con más frecuencia ha sido de la gran autoridad del Duque de Medinasidonia, consiguiendo por este medio respuestas tan benignas y resoluciones tan favorables que han bastado a hacerlos más insolentes y dejar a Vuestra Magestad mal servido y en un total desprecio la representación del Consejo de Aragón", razón por la cual solicitaba que en adelante no se admitiesen esas representaciones ${ }^{136}$. De este modo Velasco había desactivado toda la influencia que podía ejercer el Brazo en la Corte, y el Estamento se encontró finalmente indefenso ante la actuación del virrey.

Quizá sí que era cierto que Velasco había «enfrenado a aquel caballo y no le faltaba más que montarle" como decía Robres ${ }^{137}$. Pero la verdad es que la gloria no le duró mucho. El 13 de agosto el virrey informaba al Estamento de la llegada de la armada del archiduque Carlos y el 23 el Consell de Cent solicitaba la ayuda

131. ROBRES. Historia ..., p. 235.

132. Anales Consulares..., p. 38v.

133. LLDBM, vol. 7, fol. 303v.

134. LLDBM, vol. 7, fol. 307r.

135. LLDBM, vol. 7, s/n, entre los fols. 318-319. CASTELlví también recoge la negativa de los miembros de la corte a recibir las cartas del Brazo, Narraciones..., vol. I, p. 496.

136. AHN, Estado, leg. 2947, 23 de mayo de 1705.

137. RoBres, Historia ..., p. 235. 
de la nobleza para capitanear la coronela ${ }^{138}$. Empezaba así un nuevo asedio de la ciudad en el que la nobleza volvió a tener un papel de primer orden ${ }^{139}$. Del asedio nos interesa destacar aquellas actuaciones en que se puso de manifiesto el liderazgo del Brazo por encima del resto de los comunes ${ }^{140}$. Así, por ejemplo, resulta significativo que el Estamento fue el primer común en responder a la petición de Velasco sobre las condiciones de capitulación. Pero todavía más importante es el hecho que el Consell de Cent, antes de presentar sus condiciones, decida enseñárselas al estamento noble para que dé su visto bueno, signo bien elocuente del prestigio que había adquirido a los ojos de "la plebe". Días después, el Brazo tuvo un papel clave en la respuesta de los tres comunes a las peticiones del nuevo Rey, los conflictos para mantener el orden público, los problemas con la mulasa, los alojamientos en la sede de la Inquisición y las peticiones de la leva de un tercio y un préstamo. Sobre este último tema hay que notar que inicialmente no se convocó a la nobleza, pero la Ciudad consideró fundamental su presencia en los debates ${ }^{141}$. También hay que destacar el papel del Brazo en la redacción del juramento de Carlos III, en el que explícitamente solicitaba que se atendiese todas las peticiones que hacían la Diputación y la Ciudad $^{142}$. Con el anuncio de la convocatoria de unas nuevas Cortes, el Brazo tomó la iniciativa y propuso al resto de los comunes una reunión de abogados para redactar un primer borrador que sirviera de guía de trabajo inicial ${ }^{143}$.

Pero donde realmente se manifestó que la actitud del Estamento no había cambiado con el nuevo monarca fue en los hechos acontecidos a partir del 22 de noviembre. En esa fecha "Corrió voz que avian querido matar a Don Antonio de Paguera y Aymerich" ${ }^{144}$, lo que conllevó una serie de tumultos importantes en que se persiguió a los seguidores de Felipe V. El Brazo lideró la reacción de los comunes al hacer rondas nocturnas y poner los medios para calmar a la población ${ }^{145}$. Su actitud le mereció la felicitación del Príncipe Antonio ${ }^{146}$. Pocos días después se anunció una prórroga en el inicio de las Cortes. De manera semejante

138. LLDBM, vol. 7, fols. 317-319

139. Sobre el asedio de 1705 la mejor versión sin duda es la de MAs, E. Diari..., pp. 561-592, que hace un seguimiento casi diario del asedio. Cfr. CASTEllví, F. Narraciones..., vol. I, pp. 519-564. Entre los historiadores la referencia ineludible es PORTA, A. La victòria..., pp. 523-589.

140. Sobre el asedio cfr. MARTí, Eduard. "Les institucions Catalanes davant l'arribada de l'arxiduc Carles III. Octubre-desembre de 1705". En VV. AA. Antoni Saumell i Soler. Miscel-lània in memoriam. Barcelona: Universitat Pompeu Fabra, 2007.

141. LLDCC, 1B, II, 214, fol. 341r. y v.

142. Archivo de la Corona de Aragón, Libro de Deliberaciones de la Diputación, N-214, fol. 336r. De ahora en adelante LLDDP.

143. Cfr. LLDBM, vol. 7, fol. 418r.

144. FELIU DE la PENYA. Anales..., p. 544.

145. LLDBM, vol. 7, fol. 426r.

146. LLDBM, vol. 7, fol. 426r 
a como se hizo en 1701, el Estamento volvió a presentar una feroz protesta ${ }^{147}$. Pero a ello se añadió un decreto por el que se anulaban todas las mercedes otorgadas por Felipe V. A diferencia de la Diputación, el Brazo se opuso y encargó a sus abogados si debía o no obedecer el decreto real ${ }^{148}$. Estos últimos acontecimientos ponen de manifiesto que el Brazo estaba a dispuesto a exigir al nuevo monarca el mismo cumplimiento de la legalidad como lo hizo con Felipe V.

\section{UN BRAZO PARA LA DEFENSA DE LA CONSTITUCIONALIDAD}

Llegados a este punto, y a luz de lo expuesto en las líneas anteriores, cabe preguntarse si toda esta intensa actividad estaba marcada por un simple deseo de oponerse a los deseos de Felipe $\mathrm{V}$ o si, por el contrario, responde a un cambio notable del Brazo que le llevaba a defender la Constitucionalidad con independencia del color del monarca. A lo largo de estos años, se hizo evidente que el Brazo había defendido las constituciones con mucho más ahínco y fervor que los diputados. Cómo recordaba Pere Molas, «el Brazo se había convertido en un contra poder de la autoridad real [...], con más fuerza que la propia Generalidad " ${ }^{149}$. En episodios con la vicerregia de 1700-1701, la nueva planta de gobierno de 1702, la expulsión de Jäger, el cambio de estamento en 1703 o los encarcelamiento de 1704, el Brazo llevó la delantera a la Diputación y en muchos casos incluso a la Ciudad. Ahora bien, durante este periodo el Estamento no solo intervino activamente en los conflictos que suponían un enfrentamiento directo con el Rey, sino también en muchos otros. Una ojeada a esta actuación nos puede ayudar a valorar mejor el papel jugado por el Brazo en la difícil coyuntura de 1700-1705. El siguiente cuadro recoge esta información $n^{150}$.

147. Cfr. LLDBM, vol. 7, fol. 436r.

148. Cfr. LLDBM, vol. 7, fol. 443-445r.

149. Molas, Pere. "Felipe V y la nobleza Catalana". Conferencia pronunciada en el Real Cuerpo de la Nobleza de Cataluña, Barcelona, 4 d'abril de 2001, pp. 5-15. La cita está en la p. 10.

150. En este cuadro hemos excluido todo el tema de las embajadas y visitas que continuamente el Brazo hacía o le hacían personalidades de la Corte que pasaban por Barcelona o al mismo monarca. Así mismo también obviamos todo el tema de las procesiones y participación en actos religiosos o cívicos como la justa de 1701. 
Cuadro 1

LA ACTUACIÓN DEL BRAZO ENTRE 1700-1705

\begin{tabular}{|c|c|}
\hline 1700 & $\begin{array}{l}\text { El Brazo amenaza con no contribuir en la } \\
\text { paga del donativo por la falta de respeto a } \\
\text { las Constituciones. }\end{array}$ \\
\hline Memorial para no alojar. & $\begin{array}{l}\text { Jaume Tayadella acude al Brazo por el } \\
\text { conflicto sobre el uso de una fuente. }\end{array}$ \\
\hline $\begin{array}{l}\text { Problemas de protocolo en la funeraria de } \\
\text { la Diputación. }\end{array}$ & $\begin{array}{l}\text { Privilegios a Vic de tener Cofradía de Sant } \\
\text { Jordi. }\end{array}$ \\
\hline $\begin{array}{l}\text { Queja de los nobles de Puigcerdà porque } \\
\text { los burgueses honrados de Perpiñán tienen } \\
\text { oficios manuales. }\end{array}$ & $\begin{array}{l}\text { Conflicto por las cátedras de la } \\
\text { Universidad. }\end{array}$ \\
\hline $\begin{array}{l}\text { El CC pide al BM que acompañe las } \\
\text { representaciones que Francisco de Miquel } \\
\text { hará al rey. }\end{array}$ & $\begin{array}{l}\text { Conflicto por la inspección del correo } \\
\text { personal de algunos nobles. }\end{array}$ \\
\hline Nueva Planta de Gobierno. & Conflicto por la multa al veguer del Brazo. \\
\hline Funeraria por el Rey. & Peligro de asedio. \\
\hline Aplicación de la vicerregia. & Modificación del testamento de Carlos II. \\
\hline $\begin{array}{l}\text { Celebraciones por el nombramiento del } \\
\text { rey. }\end{array}$ & Privilegio otorgado a Mataró. \\
\hline Jurisdicción de la Real Audiencia. & Retirada de tropas del Principado. \\
\hline 1701 & 1704 \\
\hline Juramento del virrey Palma. & Causa contra Anton Planellas. \\
\hline $\begin{array}{l}\text { Nombramiento de Felip Ferran como } \\
\text { embajador. }\end{array}$ & Asedio de Barcelona. Dirección escuadras. \\
\hline Celebraciones por la llegada de la Reina. & $\begin{array}{l}\text { Escribir a los nobles de las diferentes villas } \\
\text { de Barcelona. }\end{array}$ \\
\hline $\begin{array}{l}\text { Rechazo a asistir a las celebraciones de la } \\
\text { DP. }\end{array}$ & $\begin{array}{l}\text { La dirección de la coronela y velar las } \\
\text { noches. }\end{array}$ \\
\hline $\begin{array}{l}\text { Protesta de la Cofradía de Sant Jordi por la } \\
\text { actuación del Veguer. }\end{array}$ & $\begin{array}{l}\text { El Rey solicita al Brazo que cuiden por la } \\
\text { quietud pública. }\end{array}$ \\
\hline Preparación de Cortes. & $\begin{array}{l}\text { Conflicto por la asistencia a la celebración } \\
\text { de la Diputación. }\end{array}$ \\
\hline Celebración por la Llegada del Rey. & Persecución y encarcelamiento de nobles. \\
\hline $\begin{array}{l}\text { Protesta por la prórroga en el inicio de las } \\
\text { Cortes. }\end{array}$ & $\begin{array}{l}\text { Protesta de los nobles de Cerdaña con los } \\
\text { de Rosellón. }\end{array}$ \\
\hline $\begin{array}{l}\text { Protestas por la presidencia del Brazo de } \\
\text { Cortes. }\end{array}$ & Conflicto por Honorat Pallejà. \\
\hline Protestas por los habilitadores de Cortes. & Amenaza de un nuevo asedio. \\
\hline
\end{tabular}


EL BRAZO MILITAR DE CATALUÑA DURANTE EL PRIMER GOBIERNO DE FELIPE V (1700-1705)

\begin{tabular}{|c|c|}
\hline 1702 & $\begin{array}{l}\text { Acompañar una representación del CC al } \\
\text { Rey. }\end{array}$ \\
\hline $\begin{array}{l}\text { Dar gracias al Rey por las Cortes y solicitud } \\
\text { de privilegios. }\end{array}$ & $\begin{array}{l}\text { La DP pide consejo al Brazo sobre una lista } \\
\text { de contrafacciones que va a denunciar a } \\
\text { Felipe V. }\end{array}$ \\
\hline Conflicto por la precedencia de los títulos. & $\begin{array}{l}\text { Conflicto por el registro de la casa de Josep } \\
\text { Agulló. }\end{array}$ \\
\hline $\begin{array}{l}\text { Un gaudint pide ayuda al BM por los abusos } \\
\text { en sus tierras. }\end{array}$ & Encarcelamiento de miembros del CC. \\
\hline $\begin{array}{l}\text { Conflicto por el privilegio militar a los } \\
\text { mercaderes de la Lonja. }\end{array}$ & 1705 \\
\hline $\begin{array}{l}\text { Sobre la composición del Tribunal de } \\
\text { Greuges. }\end{array}$ & Encarcelamiento de los abogados del BM. \\
\hline $\begin{array}{l}\text { Decidir cómo ha de concurrir el estamento } \\
\text { real al donativo de Cortes. }\end{array}$ & Supresión de la Conferencia. \\
\hline $\begin{array}{l}\text { Ropas del rey sin pagar los impuestos en el } \\
\text { convento de Montserrat. }\end{array}$ & Conflicto por la precedencia del Brazo. \\
\hline $\begin{array}{l}\text { Conflicto sobre la Nueva Planta de gobierno } \\
\text { en ausencia del Rey. }\end{array}$ & $\begin{array}{l}\text { Representación al Virrey sobre los nuevos } \\
\text { encarcelamientos. }\end{array}$ \\
\hline $\begin{array}{l}\text { Un grupo de nobles solicita al Brazo que } \\
\text { interceda para la aplicación del impuesto de } \\
\text { Nueva Ampra. }\end{array}$ & Oposición a las fortificaciones de la ciudad. \\
\hline $\begin{array}{l}\text { Cuestionar la designación del nuevo } \\
\text { Canciller de la Real Audiencia. }\end{array}$ & Peligro de asedio. \\
\hline $\begin{array}{l}\text { Los jurados de varias ciudades se quejan } \\
\text { de los abusos en el consumo y requisa de } \\
\text { paja. }\end{array}$ & Dirección de las escuadras. \\
\hline $\begin{array}{l}\text { El Duque de Cardona y la presidencia del } \\
\text { Brazo. }\end{array}$ & Negociar las capitulaciones de la ciudad. \\
\hline $\begin{array}{l}\text { El virrey Palma informa de la presencia de } \\
\text { la Armada enemiga. }\end{array}$ & Conflicto por la liberación de los presos. \\
\hline $\begin{array}{l}\text { Conflicto por la expulsión de Arnaldo } \\
\text { Jäger. }\end{array}$ & Rondas por la noche. \\
\hline $\begin{array}{l}\text { Conflicto por la obertura del Tribunal de } \\
\text { Contrafacciones. }\end{array}$ & $\begin{array}{l}\text { El conflicto de la mulasa y los papeles de la } \\
\text { Real Audiencia. }\end{array}$ \\
\hline Oposición a la renovación de Palma. & $\begin{array}{l}\text { La Inquisición protesta para que no se alojen } \\
\text { en su casa los soldados. }\end{array}$ \\
\hline
\end{tabular}




\begin{tabular}{|c|c|}
\hline 1703 & $\begin{array}{l}\text { Nombrar personas para debatir los temas } \\
\text { que el Rey ha solicitado a la Diputación y } \\
\text { Consell de Cent. }\end{array}$ \\
\hline Multa al Protector. & $\begin{array}{l}\text { El Rey consulta la creación de una Junta } \\
\text { Real. }\end{array}$ \\
\hline $\begin{array}{l}\text { Envío de Josep Duran para tratar el tema de } \\
\text { Jäger y otros derivados. }\end{array}$ & Aprobar el juramento del Rey. \\
\hline Sobre el privilegio de Ciudad a Cervera. & $\begin{array}{l}\text { Conferencias sobre el préstamo al rey y la } \\
\text { leva de un nuevo tercio. }\end{array}$ \\
\hline $\begin{array}{l}\text { Enfrentamiento con la Diputación sobre el } \\
\text { asunto Jäger. }\end{array}$ & $\begin{array}{l}\text { El Brazo encarga a la Conferencia la } \\
\text { preparación de las Cortes. }\end{array}$ \\
\hline Composición del tribunal de Greuges. & $\begin{array}{l}\text { El orden público y la petición del General } \\
\text { Basset. }\end{array}$ \\
\hline $\begin{array}{l}\text { Ordinaciones de la Real Audiencia sobre los } \\
\text { notarios reales. }\end{array}$ & Protesta por la prórroga de las Cortes. \\
\hline $\begin{array}{l}\text { Devolución de lo sobrante de las } 2000 \text { libras } \\
\text { semestrales de la DP. }\end{array}$ & $\begin{array}{l}\text { Los decretos que anulan las mercedes } \\
\text { concedidas por Felipe V. }\end{array}$ \\
\hline
\end{tabular}

Fuente: LLDBM; MAS, E. Diari...; CASTElLví, F. Narraciones...; Anales Consulares; Abreviaturas: BM: Brazo Militar; CC: Consell de Cent; DP: Diputación.

Gráfico $1^{151}$

NÚMERO DE TEMAS TRATADO POR AÑO

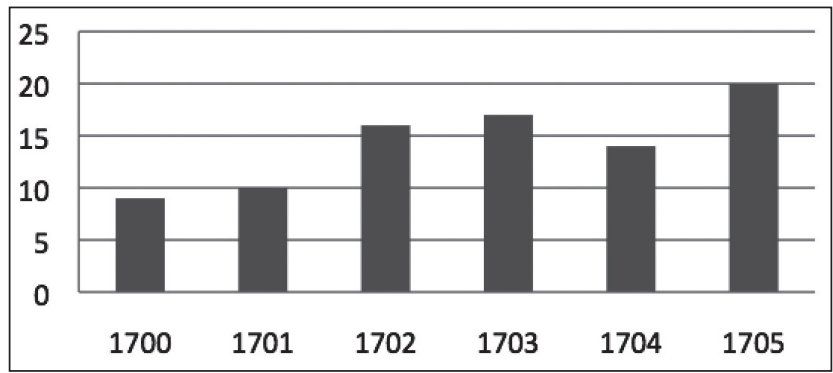

A lo largo de estos seis años el Brazo abordó 86 temas diferentes de los que en las líneas precedentes solo hemos tratado unos 45, que son los que afectan directamente con la oposición de la Corona. El resto de ellos hacen referencia especialmente a enfrentamientos entre las instituciones, peticiones de diferentes personas particulares o entidades y cuestiones militares, lo que ya pone de manifiesto la gran actividad desarrollada. Si lo que hacemos es fijar nuestra atención en

151. La fuente de este gráfico y de los siguientes es la misma que el Cuadro 1. 
el número de temas tratados observamos que la actividad del Brazo fue aumentando progresivamente, lo cual es indicativo tanto del crecimiento de la tensión política como del protagonismo de la institución.

Por otro lado, podemos aproximarnos a la actividad del Brazo durante esos años a través de una clasificación de los temas analizados en cuatro ámbitos: militar, económico, constitucional y protocolo. Dentro del primer grupo englobaríamos todos aquellos que hacen referencia tanto a la defensa de la ciudad y del Principado como los derivados de los abusos en los alojamientos de soldados. Los económicos pensamos que no requieren explicación y con los constitucionales pretendemos englobar a todos aquellos que afectan al rompimiento del marco legal vigente, lo que hace referencia tanto a los encarcelamientos injustificados como el incumplimiento de los compromisos adquiridos en las Cortes. Finalmente los temas de protocolo serían una especie de cajón de sastre que engloba tanto los enfrentamientos con otros comunes por el lugar que ocupan los oficiales del Brazo en las manifestaciones públicas (celebraciones por la venida del rey, funerarias, procesiones), como las que hacen referencia a legalidad de dignidades otorgadas a otros comunes (ciudades, gremios). La distribución porcentual de estos temas se puede visualizar en el siguiente gráfico.

Gráfico 2

TEMAS TRATADOS POR POR EL BRAZO ENTRE 1700-1705

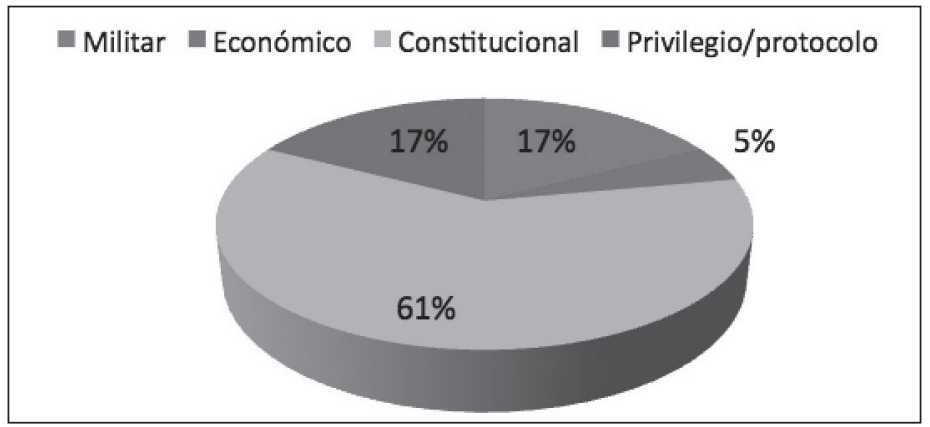

Un primer elemento que destaca es el claro predominio de los temas constitucionales (62\%) sobre el resto de actividades del Brazo, especialmente los militares (17\%) a pesar que, durante esos años, hubo dos asedios de la ciudad y dos avisos más de posible asedio (en septiembre de 1703 y agosto de 1704). Esto es indicativo de un cambio claro de las preocupaciones del Brazo, cada vez más volcado en la defensa del marco legal catalán. Ahora bien, una mirada más detallada de las actuaciones englobadas dentro de este grupo, pone de manifiesto que el Estamento no solo se limitó a oponerse a los intentos transgresores de la Corona. Uno de los elementos más claros fue el apoyo que dio el Brazo al Consell de Cent 
en asuntos que estrictamente no afectaban a sus intereses, como por ejemplo las cartas recomendatorias a Francisco de Miquel en junio de $1701^{152}$, las Cátedras de la Universidad o el asunto Pallejà. Más interesante aún es la relación con la Diputación. Por un lado encontramos momentos de plena sintonía, como los que se produjeron con el conflicto por las ropas del rey encontradas en el monasterio de Montserrat en Barcelona que no habían pagado impuestos en $1702^{153}$ o la inspección de la casa de Josep Agulló en $1704^{154}$. Por otro lado, el Brazo, a parte de los conocidos casos de la vicerregia y de Jäger, también tuvo una actitud muy agresiva con el enjuiciamiento al diputado eclesiástico, al que se le encontró ropas de contrabando en su casa (julio de 1703 y febrero de 1704) ${ }^{155}$. Especial importancia tuvo el conflicto por la designación de Emmanuel Santjust como Canciller de la Real Audiencia en septiembre de 1702. El Brazo cuestionó en solitario la designación y la Diputación recordó al Estamento que tenía orden de la reina de que el Brazo lo registrara y en caso de que no lo hiciera le informase ${ }^{156}$. A todos estos, aún podríamos añadir los continuos enfrentamientos por la composición del Tribunal de Greuges que ya hemos podido ver, la defensa de los notarios causídicos frente a los reales, o la defensa de miembros concretos de la nobleza por los abusos de un común, como es el caso de Jaume Tayadella con la Ciudad de Castelltersol en $1702^{157}$. En todos ellos se percibe con la claridad que el Brazo no solo defendía los intereses puramente estamentales sino que trascendía las fronteras de clase para interesarse por todo el Principado ${ }^{158}$.

Respecto a la cuestión militar se observa una clara continuidad con las mismas dinámicas de la segunda mitad del siglo XVII. Tanto en el asedio de 1704 como el de 1705 el Brazo destacó en la dirección de la coronela, las rondas nocturnas para mantener el orden público o la llamada a que la nobleza hiciera levas en sus tierras como sucedió en $1704^{159}$. De este asedio, por ejemplo, se conserva la lista de los turnos de guardia del Brazo Militar ${ }^{160}$. La actuación del Brazo para mantener el orden justo después de la llegada del Archiduque es digna de mención, especialmente los medios para proteger virrey Velasco la noche del 12 de octubre $^{161}$. No deja de ser paradójico que precisamente el virrey que tantas ene-

152. LLDBM, vol. 6, fol. 81v.

153. DGC, vol. X, p. 131 y ss.

154. LLDBM, vol. 6, fol. 256r.

155. Cfr. LLDBM, vol. 6, fol. $953 \mathrm{v}$

156. LLDBM, vol. 6, fol. 477 .

157. LLDBM, vol. 6, fol. 949r. El conflicto era por el uso de una fuente natural para regar las tierras.

158. LLDBM, vol. 6, fol. 926r.

159. LLDBM, vol. 7, fol. 11v i ss.

160. LLDBM, vol. 7, fol. 15v

161. El Libro de deliberaciones nos ha dejado un excelente relato de lo que sucedió en esa coyuntura y el papel que tuvo el Brazo. De hecho el mismo Protector estuvo en el palacio del virrey intentando calmar a la población que amenazaban al antiguo virrey. Cfr. LLDBM, vol. 7, fols. 363-366. 
mistades se supo granjear del Brazo Militar durante los años anteriores, al final salvara la vida en parte gracias a la actuación del Estamento. Por otro lado, en marzo de 1700 todavía constatamos que perdura el eterno enfrentamiento con la corona por el derecho de los nobles de no alojar soldados ${ }^{162}$. Además también hay que destacar el apoyo que el Estamento dio a los comunes de los pueblos de alrededor Barcelona en agosto de 1702 por los abusos de las tropas en la requisa de pajas, lo que le llevó a hacer una protesta formal al virrey ${ }^{163}$. Además constatamos que el Brazo es uno de los comunes a los que el virrey informaba del paso de la armada enemiga cerca de las costas, para que estuviera preparado, como sucedió en 1702, 1703 y 1704. Lógicamente este conjunto de medidas granjearon el prestigio de la institución desde la perspectiva real y por eso en 1703 Felipe V consideraba que podía retirar tropas del Principado e informaba al Brazo, el cual, por consejo de la Conferencia, daba su visto bueno a la decisión ${ }^{164}$. Todo ello es un signo evidente que la actitud del Brazo, como institución siempre fue fiel a la Corona. Precisamente por eso, la sorpresa tan grande que generaban las críticas del Estamento al incumplimiento de la legalidad.

Otro de los grandes temas que ocuparon su actuación durante esos años fueron los derivados del protocolo y las dignidades del estamento. De los más conocidos es el enfrentamiento con la Diputación por el lugar que los oficiales del Brazo debían ocupar en las manifestaciones públicas (funerarias o los actos de bienvenida). El conflicto procede ya de 1673 cuando los diputados consideraron que los asesores de la Generalitat debían preceder a los oficiales del Brazo ${ }^{165}$. A partir de allí tuvo lugar un conjunto de enfrentamientos que se visualizaron en las negativas del Brazo a asistir a las invitaciones que le hacían los diputados en abril y noviembre de 1700 , marzo de 1701 y julio de $1704^{166}$. No eran discusiones banales, pues tras ellos se esconde la manifestación pública del prestigio social de cada común. En el contexto de una Diputación que cada vez defendía con más debilidad la constitucionalidad, no era extraño que el Brazo exigiese una posición más destacada en los actos públicos, acorde al papel real que estaba ejerciendo en la vida política del país. Otro punto destacado en las cuestiones de protocolo fue la celebración de actos como el nombramiento o la llegada del rey. Estos acontecimientos también podían tener una alta significación política. Así, por ejemplo, el 22 de diciembre de 1700, siguiendo el consejo de la Conferencia, el Brazo acordaba no hacer demostraciones públicas por Felipe V hasta que

162. Cfr. LLDBM, vol. 6, fol. 54r. Tanto en 1650 como en 1684 y 1698 el Brazo había hecho memoriales justificativos sobre este este tema. El memorial que se finalizó en 1700 era el tercero que escribía en los últimos 50 años.

163. LLDBM, vol. 6, fol. 449v.

164. LLDBM, vol. 6, fol. 1068r. y v.

165. Cfr. MARTí, Eduard. "L'Assentament Institucional del Braç Militar i les conferències dels comuns". Recerques, 2014. En prensa.

166. LLDBM, vol. 6, fol. 74v., 168r., 274r. y vol. 7, fol. 75v. 
se juraran las constituciones, pero, unos meses más tarde, cuando ya estaba a punto de llegar a la ciudad condal para la celebración de Cortes, acordaba, a petición de la Diputación, revitalizar la Cofradía de San Jordi para agasajar al Rey $^{167}$. Tema diferente es el conflicto por la precedencia de la nobleza titulada en las reuniones del Estamento. El enfrentamiento, que empezó en 1693, dio lugar a una fuerte disputa que solo se solucionó parcialmente en las Cortes de 1705-1706 ${ }^{168}$. Durante estos años hubo varios intentos de solución infructuosos en 1701, 1702 y 1705, como bien lo experimentó el duque de Cardona en agosto de $1702^{169}$. Dentro este apartado entran también las quejas de diferentes cofradías de nobles por situaciones irregulares, como la que en 1700 hicieron los nobles de Puigcerdà porque los burgueses honrados de Perpiñán ejercían oficios manuales ${ }^{170}$, y las numerosas consultas al Brazo sobre la legalidad de la concesión de algunas mercedes, como puede ser el privilegio de Ciudad a Cervera y Mataró o la de tener Cofradía de San Jordi a Vic ${ }^{171}$.

Finalmente otro campo donde el Estamento acabó interviniendo, si bien con una intensidad menor, fueron temas de carácter económico. En 1702 el Brazo tuvo un papel activo en la fijación de cómo el estamento real contribuiría al pago del donativo, para lo cual nombró una junta especial ${ }^{172}$. Meses más tarde, como demostración evidente de la fuerte integración económica de la nobleza con los estamentos socialmente más bajos ${ }^{173}$, un grupo de nobles, entre los que destacaban Felip Ferran, Joan Llinás o el cronista Narcís Feliu de la Penya, exigían al Brazo que interviniera para que se aplicara la cesión del impuesto de Nueva Ampra aprobada en Cortes ${ }^{174}$. Su prestigio fue tal que, poco después del asedio de 1705, la Ciudad solicitó la entrada del Brazo en las conferencias que debatían sobre el préstamo que se debía hacer al archiduque ${ }^{175}$. Estas medidas muestran el protagonismo que tuvo el Brazo durante esos años como consecuencia de que los comunes contaran con él en cuestiones más variadas y que aparentemente estaban alejadas de su actividad inicial. De hecho, la penetración del Brazo en temas económicos fue en aumento a lo largo de los años siguientes, como lo demuestra su intervención en el debate de los reales de a ocho recortados en setiembre de

167. LLDBM, vol. 6, fols. 185r. y. 406r.

168. Una explicación del conflicto se puede encontrar en la versión que dieron los títulos que se conserva a la Biblioteca de l'IUHJVV: Señor, Los Títulos del Principado de Cataluña...

169. LLDBM, vol. 6, fol. 464r

170. LLDBM, vol. 6, fol. 68r.

171. LLDBM, vol. 6, fol.839r; 1027r. y 948v.

172. LLDBM, vol. 6, fol. 367r

173. GARCÍA EsPuCHE, Albert. Barcelona entre dues guerres: economia i vida quotidiana 16521714. Vic: Eumo 2004.

174. LLDBM, vol. 6, fol.426v.

175. LLDDP, N-214, fol. 341r. y v. 
1707, la compra de la Bailía Real en 1712 o su implicación en el levantamiento de fondos durante el asedio de $1713^{176}$.

Llegados a este punto cabe preguntarse por la distribución temporal de los temas tratados por el Brazo durante esos años. El siguiente cuadro recoge esta información.

Gráfico 3

Distribución TEMPORAL DE los temas tratados POR POR El BraZO Militar ENTRE 1700-1705

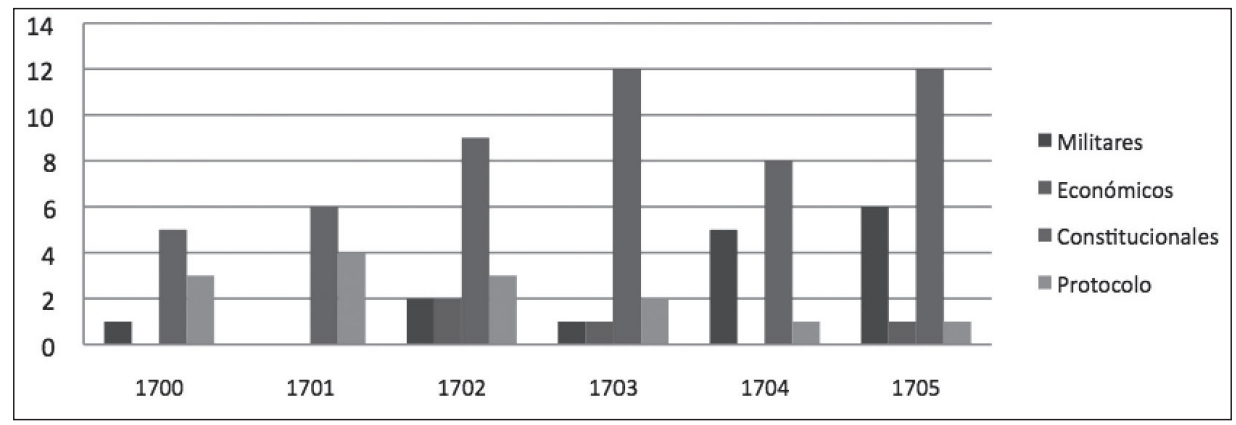

Las cuestiones relacionadas con la defensa de las Constituciones fueron siempre la principal preocupación del Brazo, especialmente el año 1703 y 1705, en los que suponen más del $50 \%$ de los temas abordados. Por otro lado, el gráfico también permite observar la creciente tensión política que se ha expuesto en las líneas anteriores y que culminó con el rompimiento de 1705. Otro dato relevante es ver que las cuestiones militares fueron uno de los principales problemas, especialmente a partir de la declaración de guerra por parte de Austria en 1702, mientras que las cuestiones de protocolo adquieren un mayor protagonismo durante los años de paz (1700-1701).

Otro tema interesante de valorar es el liderazgo del Brazo Militar a nivel institucional. Una manera de hacerlo sería analizando quién tuvo la iniciativa en la solicitud de los temas en que intervino. Esto no siempre resulta fácil de diferenciar, pues en algunos casos varias instituciones tomaron la iniciativa simultáneamente. Aun así, nos hemos arriesgado a hacerlo. Para ello diferenciamos los casos en que el Brazo inició el conflicto de los que son fruto de peticiones de la Ciudad, de la Diputación, del Rey/virrey, particulares, la Conferencia y "otras instituciones", que incluiría a los comunes de las diferentes ciudades del Principado. El resultado de este estudio queda reflejado en el siguiente gráfico.

176. MARTí, Eduard, La Conferencia..., pp. 160-163 y 187-188. 
Gráfico 4

INICIATIVA EN LA ACTUACIÓN DEL BRAZO 1700-1705

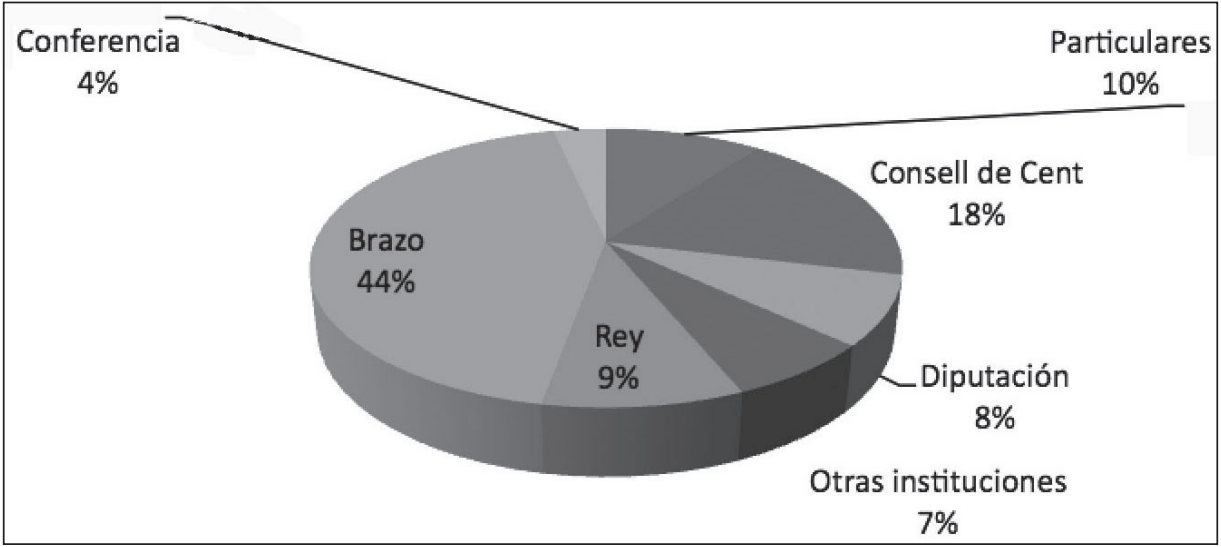

Durante esos años se constata el claro liderazgo del Brazo en la mayor parte de los temas en que participó, en los cuales fue el primero en salir en la defensa de la Constitucionalidad y recordar al resto de los comunes sus obligaciones. No vale la pena entrar ahora a enumerarlos, pues ya los hemos podido ver anteriormente. Ahora bien, un dato muy relevante es que el 18\% de los temas fueron a petición del Consell de Cent, entre los que destacan, a parte de los relacionados con la defensa de la ciudad, las cartas que el Brazo hizo para Francisco de Miquel en 1700, el asunto de las cátedras de la universidad en 1703, Honorat Pallejá y la petición de apoyo en los encarcelamientos en 1704 y las peticiones para que el Brazo se incorporara a las Conferencias posteriores al asedio de 1705. Esto es indicativo de esa cercanía entre las dos instituciones que hablábamos al inicio de este artículo, que también se visualizó en la unión que mostraron en la Conferencia de los tres comunes. No olvidemos que el famoso Josep Duran fue enviado por el Brazo, pero también representó los intereses de la ciudad. El recurso que hizo el Felipe V y la Diputación al Brazo fue muy menor. El rey sobre todo acudió al Brazo para informarle de acontecimientos (su llegada o de la reina, la retirada de tropas, el decreto de cambio de estamento, etc.) y pedir su ayuda en la defensa de la ciudad, pero en ningún caso para consultarle la legalidad de sus decisiones. Esta es sin duda la gran diferencia con el archiduque Carlos que, en los dos meses que gobernó en 1705, consultó a los comunes el modo cómo debía hacer juramento, la legalidad de hacer crear un Consejo Real y la posibilidad de hacer un préstamo y levantar un tercio. La Diputación, por su lado, acudió sobre todo para las cuestiones de protocolo, si bien cabe destacar la ayuda que solicitó con las ropas de contrabando del rey en 1702 y en la convocatoria del Tribunal de Contrafacciones en 1704. 
Otro tema interesante es la variedad de personas e instituciones que a lo largo de esos años acudieron al Brazo para asuntos de lo más variados. De hecho si sumamos los porcentajes de los "particulares" con los de "otras instituciones" y la Conferencia, vemos que en total suponen el 21\% de las actuaciones en las que participó el Brazo, lo que muestra el peso que tenían sobre él. Tanto en 1700 como en 1704 los nobles de Cerdaña requirieron la ayuda del Brazo; en 1701 fue la Cofradía de San Jorge y en 1702 Arnald Jäger y las ciudades de los alrededores de Barcelona por el abusos en la requisa de pajas; en 1703, Cervera, Vic y Jaume Tayadella y en 1705 encontramos tanto a la Inquisición pidiendo la protección del Brazo para evitar que se alojasen tropas en su casa como el general Basset solicitando su intercesión para que el archiduque decidiera enviar tropas a Valencia ${ }^{177}$. Esta gran variedad de personas que acuden al Brazo para solucionar sus problemas muestra el prestigio que había adquirido la institución con el correr de los años, de manera que cada vez era menos visto como un "gremio de la nobleza" que velaba solo por sus intereses estamentales. La lectura de todos esto hechos también pone de manifiesto que difícilmente su actuación se guió exclusivamente por la oposición sistemática a Felipe V.

\section{VALORACIONES FINALES}

Hace ya muchos años Núria Sales se dio cuenta de que el Brazo Militar y la Conferencia de los Tres Comunes fueron "decisius i potser decididors en la presa del partit austriacista de 1705 i al llarg de la Guerra de Successió, ${ }^{178}$. Resulta muy difícil poder explicar la historia del primer gobierno de Felipe V en Cataluña sin destacar el protagonismo jugado por el Estamento Militar, especialmente por su férrea defensa del marco constitucional. Los mismos diputados lo reconocían en diciembre de 1704: "[el Brazo] ha sempre manifestat defensar no sols las prerrogativas de la Generalitat [...] ja també per la defensa dels privilegis de tot el Principat" ${ }^{179}$. En la misma línea, en 1715 José Patiño destacaba que, "de algunos años á esta parte, por descuido ó tolerancia de los ministros, [el Brazo] se había hecho formidable y se entrometía en todas las materias de estado, publicándose celadores de la observancia de sus fueros ${ }^{180}$. La amplitud de cuestiones que abordó entre 1700-1705 pone de manifiesto que no exageraba: la planta de gobierno, los encarcelamientos injustificados, la vicerregia, la defensa de la ciudad ante los asedios, la composición del Tribunal de Greuges y de Contrafacciones, etc. Es en este punto donde radica la diferencia esencial entre el Brazo de la segunda mitad

177. LLDBM vol. fol. 372r. y fol. 426r. y ss.

178. Sales, Núria. "Diputació, síndics i diputats. Alguns errors evitables". Pedralbes, 1995, 15, pp. 95-102, p. 96.

179. LLDBM, G-69, vol. VII, fol. 256r.

180. Sanpere i MIQuel, Santiago. Fin de la Nación Catalana. Barcelona: Base, 2001, p. 677. 
del siglo XVII y el del XVIII: la defensa de la Constituciones. Como decía Pere Molas, el Brazo se presentaba "en materias de estado como defensores del sistema constitucional catalán»181.

Esta actitud no se explica solo por la existencia de una élite cerrada que controlase la institución y que hubiese tomado parte el partido por el pretendiente austríaco $^{182}$. La coherencia y amplitud de la actuación del Brazo durante esos años trasciende en mucho los intereses puramente estamentales. Buen ejemplo de esto es lo sucedido en las semanas posteriores al asedio de 1705. El Brazo no perdonó ni a Felipe V ni al archiduque Carlos III que prorrogasen las Cortes. Es más, del mismo modo que se enfrentó a los encarcelamientos injustificados de Velasco, también lo hizo al decreto del archiduque que anulaba todas las mercedes concedidas por Felipe V. A pesar del rechazo que sentía por Velasco, el estamento no dudó en salir en su defensa durante esos días. No podemos detenernos ahora, pero lo cierto es que con el archiduque Carlos III, el Brazo no tuvo una actitud mucho más permisiva que con Felipe V. Así, continuó denunciando la incompetencia de las tropas, los abusos en los alojamientos, puso dificultades a recortar los reales de a ocho o exigió la retirada del Epítome, por citar solo alguno de los conflictos más conocidos ${ }^{183}$. En última instancia, como recordó Albareda, los comunes, y aquí nosotros pensamos que habría que hablar especialmente del Brazo Militar, eran más fieles a las leyes de la patria que no a una dinastía monárquica concreta ${ }^{184}$.

Por otro lado, no se puede hablar del Brazo sin hacer una referencia, aunque breve, a la Conferencia de los tres Comunes, de la cual, como sabía el Consejo de Estado en 1704, "el mismo Brazo era la parte más poderosa" ${ }^{185}$. Los estudios ponen de manifiesto que el Brazo fue el principal impulsor de la Conferencia y el que tendió a concederle más competencias ${ }^{186}$. A la vez, la Conferencia se convirtió en un instrumento que permitió al Brazo participar en cuestiones políticas en las que de otro modo no hubiera tenido parte ${ }^{187}$. Ejemplos de ello serían la apertura del Tribunal de Contrafacciones o la presión que ejerció el Brazo para que los diputados retirasen el Epítome. Pero no solo eso. En el trasfondo de este crecimiento del Brazo, lo que se oculta es el proceso de "minorización" política de la Diputación,

181. MOLas, Pere. "Felipe V...", p. 10.

182. Simón I TARrES, A. Del $1640 \ldots$, p. 298.

183. Una aproximación al papel del Brazo durante esos años, MARTí, E. La Conferencia..., p. 134-168.

184. Cfr. Albareda, Joaquín. El "Cas dels catalans". La conducta dels aliats arran de la Guerra de Successió (1705-1742). Barcelona: Fundació Noguera, 2005.

185. AHN, Estado, leg. 272, exp. 46. 11 d'octubre de 1704

186. MARTí, E. La Conferencia..., p. 283.

187. MARTí, E. La Conferència dels tres comuns i el Braç Militar. Tesis doctoral. Barcelona: Universitat Pompeu Fabra, 2008, p. 559. 
de la cual ya hemos podido hablar en otras ocasiones ${ }^{188}$. Además hay que valorar que la masa social que representaba a la institución también formaba parte de las reuniones del Consell de Cent. Es precisamente por esta razón que la pequeña nobleza que participaba en las reuniones del Brazo Militar tendió a asociarse más con la Ciudad que no con la Corte ${ }^{189}$. De hecho, se ha demostrado que de los 216 nobles y ciudadanos que participaron en el Consejo de Ciento entre 1698 y 1714, 76 también lo habían hecho en el brazo, lo que supone el 35\%. En el fondo, ya lo dijo Elliott: "El Braç Militar existía simplement per expressar les opinions de l'aristocràcia, i especialment la de Barcelona "190.

A la luz de lo que hemos expuesto, y bajo la perspectiva del conflicto sucesorio, pensamos que el posicionamiento del Brazo Militar durante la Guerra de Sucesión, no se explica solo por la defensa de "sus privilegios y las importantes parcelas de poder y de representación "191, sino sobre todo por una actitud firme de la defensa del marco constitucional. En esto superó ampliamente a los diputados e igualó, como mínimo, al Consejo de Ciento. Imagen bien clara de esta realidad es el hecho que, el 11 de septiembre de 1714, cuando el Conseller en Cap cae herido, es el Protector del Brazo Militar el que llevó el pendón de Santa Eulalia. Y horas más tarde, cuando tuvo que abandonarlo para ocuparse de otras obligaciones, fue Josep Mata, consejero noble del Brazo, el que tuvo tal honor ${ }^{192}$. Curiosamente no había ningún diputado.

\section{BIBLIOGRAFÍA}

\section{Fuentes manuscritas}

Archivo Histórico Nacional. Consejo, Legajo 2377. Estado, legajos, 272, 440 (2), 1605, 2947.

Archivo de la Corona de Aragón. Generalitat, G-69, G-225 y N-214.

Archivo de General de Simancas. Estado, leg. 7838.

Archivo histórico de la Ciudad de Barcelona. Libro de Deliberaciones del Consell de Cent, 1B, II, 211.

Biblioteca de Catalunya. Anales Consulares, Manuscrito 173, 3 vols.

Biblioteca de L'IUHJVV. Publica Notícia del acierto... Diputació i Catalunya, Tomo III.

Señor, Los Títulos del Principado de Cataluña...

Biblioteca del Seminario Consular de Barcelona.

MAS, Emmanuel, Diari des del novembre del any 1700 fins a l'octubre del any 1705, Documento 419.

188. MARTí, E. La Conferència..., p. 622.

189. Sobre este tema ver las obras citadas de García EsPuche, Albert. Barcelona ...; Amelang, J. La formación... y MARTí, E. La Classe dirigent...

190. ElliotT, J. H. La revolta catalana, 1598-1640. Barcelona: Vicens Vives, 1966, p. 154.

191. Albareda, J. La guerra de Sucesión..., p. 172.

192. Castellví, F. Narraciones..., vol. IV, p. 253. 
2. Fuentes editadas

Ballcallar y Sana, Vicente. Comentarios de la guerra de España. Madrid: Atlas, 1957.

CAstellví, Francisco, Narraciones Históricas. Madrid: Fundación Francisco Elías de Tejada, 1997, 4 vols.

Constitucions $i$ altres drets de Cathalunya: compilacions de 1495, 1588-1589, i 1704. Edición facsímil. Barcelona: Base, 2004, 2 vols.

Dietaris de la Generalitat de Catalunya. Barcelona: Generalitat de Catalunya, 2007, 10 vols. Feliu de la Penya, Narcís. Anales de Catalunya. Ed. facsímil. Barcelona: Base, 1999.

LóPez de Mendoza, Agustín. Historia de las Guerras Civiles de España. Zaragoza: Diputación Provincial de Zaragoza, 1882, 2 vols.

Manual de Novells Ardits. Barcelona: Ayuntamiento de Barcelona, 1982-1975, vol. XXII.

\section{Bibliografía crítica}

ALABrús, Rosa. Escrits polítics del segle XVIII. Vic: Eumo, vol. 4, 2007.

Albareda, Joaquin. Política, religió i vida quotidiana en temps de guerra (1705-1714). Vic: Eumo, 2001.

ALBAREDA, Joaquin. Els catalans $i$ Felip $V$, de la conspiració a la revolta, 1700-1705. Barcelona: Vicens Vives, $1993^{3}$.

AlBAREDA, Joaquin. "Les Corts de 1701-1702 i de 1705-1706. La represa del constitucionalisme". En Constitucions, capitols $i$ actes de cort 1701-1702 i 1705-1706. Barcelona: Parlament de Catalunya, pp. XVII-XLV.

ALBAREDA, Joaquin. El "Cas dels catalans". La conducta dels aliats arran de la Guerra de Successió (1705-1742). Barcelona: Fundació Noguera, 2005.

AlBAREDA, Joaquin. La Guerra de Sucesión de España (1700-1714). Barcelona: Crítica, 2010.

Amelang, James. La Formación de una clase dirigente. Barcelona: Ariel, 1986.

BARREDA Fontes, José M. y CARRETERO ZAMORA, Juan M. "Una fuente inédita sobre la Guerra de Sucesión: memoria anónima sobre el sitio de Barcelona de 1705". Hispania, 1980, 40, pp. 631-668.

Batrolí, Jaume. "La Cort de 1701-1702: un camí truncat”. Recerques, 1979, 9, pp. 57-75.

Fuuvià, Armand de. "Precedents històrics del reial cos de la noblesa de Catalunya". Conferencia pronunciada en el Real Cuerpo de la Nobleza de Cataluña. Barcelona: 1991.

FERNÁNDEZ, M. "Espionatge borbònic a la Barcelona austriacista. Un informe de l'any 1706". En Actes del I Congrés d'Història Moderna de Catalunya. Barcelona: Diputació de Barcelona, 1984, pp. 243-252.

GARCÍA ESPUCHE, Albert. Barcelona entre dues guerres: economia i vida quotidiana 16521714. Vic: Eumo 2004.

GAY, Josep María. El corregidor a Catalunya. Madrid: Marcial Pons, 1997.

MARTí, Eduard. "Conflictivitat institucional: La Conferència dels Comuns de novembre de 1700". Pedralbes, 2003, 23/2, pp. 209-232.

MARTí, Eduard. "L'Assentament Institucional del Braç Militar i les conferències dels comuns". Recerques. En prensa, 2014.

MARTí, Eduard. "Les institucions Catalanes davant l'arribada de l'arxiduc Carles III. Octubredesembre de 1705". En VV. AA. Antoni Saumell i Soler. Miscel-lània in memoriam. Barcelona: Universitat Pompeu Fabra, 2007. 
MARTí, Eduard. La classe dirigent catalana. Barcelona: Fundació Noguera, 2009.

MARTí, Eduard. La Conferencia de los Tres Comunes. Lleida: Milenio, 2008.

Molas, Pere. "Felipe V y la nobleza Catalana". Conferencia pronunciada en el Real Cuerpo de la Nobleza de Cataluña, Barcelona, 4 de abril de 2001.

Morales Roca, Francisco. Próceres habilitados en las Cortes del Principado de Catalunya, siglo XVII (1599-1713). Madrid: Hidalguía, 1983.

Oliva, Benet. "Conflicte ideològic i control de la Universitat. La "verdad triunfante" de Narcís Feliu de la Penya (1682)". Recerques, 2002, 44, pp. 181-198.

Pi i Arimon, Andrés. Barcelona Antigua y Moderna. 1. ${ }^{a}$ ed. Barcelona: Librería Politécnica de Tomás Gorchs, 1854, 2 vols

PORTA, Antoni. La victòria catalana de 1705. 1. ${ }^{\mathrm{a}}$ ed. Barcelona: Pòrtic, 1984.

SAlES, Núria. "Diputació, síndics i diputats. Alguns errors evitables". Pedralbes, 1995, 15, pp. 95-102.

SAlvador, Felipe. "El Real Cuerpo de la Nobleza, antiguo Brazo Militar del Principado de Cataluña y condados de Rosellón y de Cerdaña. Hidalguía, 1957, 5, pp. 369-376.

SAnPere i Miquel, Santiago. Fin de la Nación Catalana. Barcelona: Base, 2001.

SERRA, Eva. "Voluntat de sobirana en un context de canvi dinàstic". En VV. AA. Una relació difícil. Catalunya i l'Espanya Moderna. Barcelona: Base, 2007, pp. 109-180.

Simón i TARres, Antoni. Del 1640 al 1705. Valencia: Publicacions Universitat de Valencia, 2011.

SoldeVILA, Ferran. "La presó de Pau Ignasi Dalmases i Ros, enviat de la ciutat de Barcelona a Felip V (1705)". En Homenatge a Antoni Rubió i Lluch. Barcelona: Institut d'Estudis Catalans, 1936, pp. 481-498.

SOLDEVILA, Ferran. Barcelona sense universitat i la restauració de la universitat de Barcelona. 1714-1838. Barcelona: Universitat de Barcelona, 1938.

TORRes RiBÉ, Josep M. La Guerra de Successió $i$ els setges de Barcelona. Barcelona: Rafael Dalmau. 1999. 